\title{
Competition and "blinders": A duopoly model of information provision
}

\author{
Ruxandra Ciupagea* \\ NERA Economic Consulting
}

\begin{abstract}
This paper analyses the effect of competition on information provision, consumers' decision of getting informed and welfare. For this, we construct a model of duopolistic competition in the presence of switching costs, which can be easily understood inside the framework of the mobile telephone market. We find that a monopoly achieves the first best (even if it is not beneficial for consumers) because the firm has incentives to provide information freely. On the contrary, competition may give firms incentives to hide information. Consequently, we provide some regulatory support for policies that decrease competition and policies that make information concealing costly.
\end{abstract}

Keywords: mobile telephone market, switching costs, information provision.

JEL classification: D43, L63, L96.

\section{Resumen}

Este trabajo analiza el efecto de la competencia en el suministro de información, la decisión de los consumidores de informarse y el bienestar. Para ello, se usa un modelo de competencia duopolística en presencia de costes de cambio, que puede entenderse dentro del marco del mercado de la telefonía móvil. Nuestro principal resultado muestra que un monopolio logra el first best (aunque no sea beneficioso para los consumidores), ya que la empresa tiene incentivos para proporcionar información de forma gratuita. Por el contrario, la competencia puede dar a las empresas incentivos para ocultar información. Por lo tanto, ofrecemos apoyo regulatorio a las políticas que reducen el grado de competencia y a las políticas que hacen que ocultar información resulte costoso para las empresas.

Palabras clave: mercado de la telefonía móvil, costes de cambio, suministro de información.

Clasificación JEL: D43, L63, L96.

\section{Introduction}

Every single, not special day in a typical consumer's life is filled with decisions that have to be taken. From unimportant to life-changing aspects, consumers continuously have to choose among different options. However, there are many situations in which consumers are not in possession of all the relevant information at the

* This paper is a revised version of the Master Thesis presented in partial fulfilment of the 20082010 Master in Economics and Finance at the Centro of Estudios Monetarios y Financieros (CEMFI). I want to thank Gerard Llobet and Guillermo Caruana from CEMFI and Michael Manove from Boston University, for comments on an earlier version of this paper. I am also grateful for the support received from NERA Economic Consulting. Any opinions, possible mistakes or omissions in this article are solely my own, and do not necessarily represent the view or position of these persons, the institutions they represent or NERA Economic Consulting. 
moment when the decision must be taken. Take the well-known "market for lemons" as an example. When buying a second-hand car, a consumer is not aware of all its hidden failures. It can only choose based on expectations or beliefs. Yet not having complete information about the car might lead him to commit a mistake.

The description above seems to fit well for all the situations in which consumers are aware of their preferences, but are not fully informed about the characteristics of a given product. A more important problem arises when, instead of not being aware of the characteristics of a given good or service that a consumer intends to buy, that consumer does not know his preferences. In this situation, even having complete information about the given good or service might still lead to a mistake, as he is, again, left to act upon beliefs. To better comprehend the significance of this issue, note that it is not only the possibility of a mistake what makes consumers worse-off when deciding on something based on beliefs. Of possibly equal importance is the fact that agents tend to be risk-averse. It is straightforward that choosing under uncertainty, as a risky action, will decrease their utility.

This motivates the fact that, in many situations, consumers are willing to gather information, either on the good or service that they are about to buy, or, more importantly, on their preferences. Yet gathering information is almost never free. It either requires time or money.

Under these circumstances, firms have a role too. In particular, they may make it harder or easier for consumers to gather information. In more economic terms, firms may affect the cost at which consumers can become informed. The problem is that firms do not always have incentives to make information available at a low cost. If the existence of uninformed consumers allows firms to extract higher surplus, they may actually take strategic decisions that make sure consumers remain so. This will most certainly have an effect on competition. Throughout all this paper, we shall try to assess the importance and implications of this effect from a social welfare point of view.

To analyze this situation, we present a reduced-form model that focuses on a market where the problems stated above are particularly present: the mobile telephone market. What distinguishes this market from more general, good providing markets is the fact that in this market consumers don't know their future consumption level when choosing a given tariff or provider. In other words, consumers do not know their preferences when making a decision related to mobile telephone service provision, so they have to choose based on beliefs. While not identical, this makes mobile telephone services more similar to experience goods than to standard goods. That is, goods which consumers have to try in order to learn how much they value. Prior literature sustents this idea. The paper by Miravete (2003) confirms that, while consumers act rationally when choosing whether to move or not from a flat tariff to a measured service (variable tariff), it is indeed true that some of them make systematic mistakes based on wrong expectations about their future telephone usage.

Of course, consumers have the possibility to acquire information when deciding 
between providers and tariffs. Information gathering in this setting may be translated into careful looks into past invoices, in order to understand consumption, or Internet searching for a better comprehension of the characteristics of all the available tariffs. But, as mentioned before, this search for information comes at a cost, which in this particular situation can be seen as an opportunity cost of time. Moreover, it makes sense to believe that consumers are heterogeneous in their cost of becoming informed, as searching Internet and bills for the best option does not imply the same opportunity cost of time for a college student as for a CEO. Consequently, we model consumers as being, not only heterogeneous in their valuations for the mobile telephone service, but also heterogeneous in their information cost.

In addition to this, the mobile telephone market is a market in which switching costs are present. Here, switching costs can be seen, in principal, as contractual switching costs. Consumers have to pay some amount of money if they want to switch firms before a certain amount of time has passed since the contract has been initially signed. So, in summation to the lack of information, switching costs might also act as a loss of efficiency enhancer, as they lock-in consumers to a given firm and decrease the level of competition.

It is true that previous literature has already thoroughly analyzed markets with consumer switching costs. However, an insight into previous studies on the matter seems to indicate that switching costs are generally decreasing market competition and social welfare. For instance, Viard (2007) tests the effect of switching costs on price competition in the high-growth toll-free telephone service market. In particular, he mentions the existence of two effects of switching costs. On the one hand, firms would like to charge high prices to previous purchasers, who are already locked-in due to the existence of switching costs. On the other hand, they would like to charge low prices to unattached consumers who offer a high future profitability. His results indicate that, when price discrimination between existent and new consumers is not possible, the firm's incentive to charge a higher price to locked-in consumers exceeds its incentive to capture new consumers. In particular, he finds that the largest firm in the market reduced its margin as a result of a decline in switching costs, hence switching costs made the market less competitive.

In addition to this, Klemperer (1995) notes that switching costs dampen competition by making ex ante identical homogeneous products heterogeneous ex post. Moreover, Klemperer (1987) finds that switching costs harm social welfare. The reason is that, even if switching costs are not actually incurred, they lead to an allocative inefficiency: firms produce too much in the first period, at a low price to capture consumers, and too little in the second one. Consequently, Klemperer's model provides some support for regulatory policies that reduce switching costs.

While similar to Klemperer's conclusions from the point of view that in equilibrium, no switching costs are incurred, our results indicate quite the opposite. High switching costs might be recommended to improve social welfare. The reason is that, in our model, high switching costs reduce the level of market competition, and provide incentives to the firms to make information cheap. 
To be more specific, we find that the first-best can be achieved within a monopoly setting, even if it is in the context of a zero consumer surplus. The intuition behind this result comes from the fact that the monopolist provides information freely in order to extract the entire surplus from consumers with high valuations for the product (this defines a niche-targeting strategy). Even if consumers gain nothing, this saves in information and risk-aversion costs, as in equilibrium everyone becomes informed, at a zero cost. On the contrary, harsh competition reduces social welfare ${ }^{1}$. Firms can no longer exploit high valuations consumers, even if these last ones are fully aware of their type. The reason is that competition limits prices in the market. Under these circumstances, a full-market strategy, achieved through lack of information provision, becomes optimal. Consequently, we provide support for regulatory policies that either increase switching costs, or limit the degree in which firms can hide information from consumers ${ }^{2}$.

Somehow more similar to ours from a switching costs effect on welfare point of view is the paper by Shi et al., (2006). The authors study how a reduction of consumers switching costs (achieved through the implementation of a regulatory policy called Wireless Number Portability, or WNP) may affect market competition in the wireless telecommunication industry. In particular, WNP was intended to intensify price competition. Nevertheless, the authors find that a reduction in switching costs may actually help accelerate the process of market concentration, obtaining the opposite effect to the desired one, of improving competition level on the market. However, in their model, this effect is due to the existence of positive interconnection costs (networks charge lower user fees for the calls within the same network than for the calls between networks, which provides large networks with a competitive advantage), while in ours, as mentioned before, low switching costs are harmful because they provide firms with incentives to hide information.

Even if they do not constitute a perfect explanation for it, our results seem to describe correctly the real-world situation present nowadays in the mobile telephone market. Indeed, this market has experienced an increase in the level of competition, all over the world. While not many years ago, in many European countries there was one unique provider for mobile telephony (generally, the same firm that was also providing the fixed telephone service), nowadays an increased number of firms have gained access to the necessary technology in order to provide mobile telephone services. With the increase in competition, came, of course, a decrease in prices. Tariffs are much lower today than they were ten years ago. However, while indeed tariffs are lower, they are also more complicated. What ten years ago was stated as " 25

\footnotetext{
${ }^{1}$ Our results do not support lack of competition in the mobile telephone market per se. It is obvious that this would be harmful for consumers. Decreasing the level of competition through an increase in switching costs is only a solution for improving social welfare if firms have the possibility to make information expensive. Regulatory policies that limit firms' possibilities to hide information would be more recommendable from a consumer surplus point of view.

2 This last result comes as a direct consequence of Section 6. However, we do not perform a full analysis of this issue, as it lies outside the scope of this paper.
} 
cents/minute, 25 cents/SMS" is stated today under different shapes and colours. We have flat tariffs, flat tariffs with limited access to the Internet, flat tariffs with $24 \mathrm{~h}$ access to the Internet, variable (or measured) tariffs, tariffs that come with a phone etc. This makes it difficult to know which tariff is the best. Moreover, all the "special offers" apparently designed to improve our utility might make it difficult for us to understand our consumption. We are tempted to contract all special packages of calls or messages (200 FREE messages for only 12 Euros), trying to make life cheaper. However, we lose track of our consumption and cannot know anymore whether we really needed it. Even if it is obvious that we will never have complete information on our preferences, as we cannot predict all the shocks that will affect demand in the future, so we will have to choose (mainly) based on beliefs, the facts stated above make the creation of beliefs a complicated and costly process. From an efficiency point of view, this market could have been better-off ten years ago, when all the relevant information was "on the table".

From a final conclusions point of view, our paper is more similar to literature on advertising and product design. Our results are consistent with Johnson and Myatt (2006). They propose a framework for analyzing transformations of demand that stem from changes in the dispersion of consumers' valuations, in particular, demand rotations. They find that profits are a $U$-shaped function of dispersion, and that high dispersion is complemented with niche production (the marginal's consumer's valuation is "above average"), while low dispersion is complemented by mass-market supply (the marginal's consumer's valuation is "below average"). The choice between the two extreme levels of dispersion comes given precisely by the maximum and minimum dispersion achievable (for the monopoly case, if maximum dispersion achievable is "very disperse", a monopolist might be inclined towards a niche posture).

In our model, and in a similar way to Johnson and Myatt's section on Advertising and Information Provision ${ }^{3}$, different degrees of information provision correspond to different levels of dispersion. As consumers become informed, more of them go further away from their ex-ante identical expected valuation and towards their real valuation. Hence, dispersion increases. Consequently, the monopoly outcome mentioned above (full information provision to extract surplus from the high valuation consumers) corresponds to the high dispersion, niche production setting in Johnson and Myatt. As opposed to Johnson and Myatt, who focus mainly on the monopoly case, we thoroughly analyze competition in our model. In Johnson and Myatt terminology, we find that a firm that preferred a niche posture in monopoly might prefer to become a mass-market supplier under competition. This change in preferences comes given by the fact that in competition, prices are restricted. Then extracting surplus from the small "niche" of high valuation consumers is no longer possible.

\footnotetext{
${ }^{3}$ In Johnson and Myatt's section on Advertising and Information Provision, an increased degree of information provision leads to a higher dispersion of consumers' valuation distribution function. More details are given in our Section 7.
} 
One difference with Johnson and Myatt's paper comes given by the fact that in their model on advertising, the degree of information is "imposed" to consumers, as a decision variable of the firm. In our paper, consumers have the option of choosing whether to acquire information or not. From this point of view, our framework is more similar to Bar-Isaac, Caruana and Cuñat (2010). In their model, consumers can acquire information (assess the quality of the good), at a homogeneous cost which is a decision variable of the firm. However, there are two main differences with their model. On the one hand, in our paper consumers are heterogeneous in their cost of becoming informed. On the other hand, Bar-Isaac, Caruana and Cuñat consider firm's commitment to investment. This lies outside the scope of our analysis. As a result, while we find, consistently with Johnson and Myatt, that profits are a $U$ shaped function of dispersion, they find that some intermediate marketing strategy might be optimal.

This paper is divided into eight main sections, including this introduction. Sections 2, 3, 4 and 5 form the baseline model. In Section 2 we describe our main setup. In Section 3 we analyze the monopoly case, while Section 4 presents a full analysis of the duopoly case. Section 5 summarizes our main results and treats welfare considerations.

Along all these sections, we assume that firms costlessly choose the degree of information provision. In Section 6, we relax this assumption and analyze optimal information provision strategies for the firms when "hiding" information comes a a cost.

In Section 7, we make a full comparison of our monopoly results with the ones presented in Johnson and Myatt (2006). Moreover, we show results on the competition case, presented in the Johnson and Myatt context. Section 8 concludes.

\section{The baseline model}

\subsection{Consumers}

There is a mass one of consumers, each of whom is potentially interested in buying one unit of the good. Consumers are of two types: a proportion a of high types, with a real valuation for the product of 1 , and a proportion 1-a of low types, with a real valuation for the product of 0 . Notice that, in what the mobile telephone market is concerned, a valuation of 0 or 1 for the product is a reduced-form for the fact that consumers might use the mobile phone a lot, or on the contrary, they might not need to use it at all.

Ex-ante, consumers do not know their type. This assumption makes sense in this particular market, as generally when choosing a mobile telephone provider, or a given tariff, consumers are not aware of their future consumption level, i.e., the number of calls that they will need to make in the future. Moreover, this market is characterized by the fact that consumers may spend years having mobile telephone 
service providers and using their mobile phones and still not be aware of their preferences, not only due to possible shocks to their demand (changes in lifestyle for example), but also due to the fact that, as mentioned in the introduction of this paper, complicated tariffs (or too simple ones, like flat tariffs) might "disguise" or conceal real preferences.

Nevertheless, within our setting, consumers have the possibility to learn their type, by incurring in an information cost $c$. Consumers are heterogeneous in their information cost $(c)^{4}$. We can interpret this as consumers being heterogeneous in their opportunity cost of time, where time under these circumstances may be related to the need to search the Internet for the right tariff, or the need to carefully examine past bills in order to understand their demand.

In the last place, consumers are risk-averse. As mentioned, they have the possibility to learn their type, and posterior to this, decide whether to buy or not. As an alternative, they may buy the product (or not), but choose to remain uninformed. If they buy uninformed, consumers lose $m$ from their expected valuation, due to risk aversion. Notice that in the market that we are focusing on, buying does not necessarily refer to acquiring a given good, but more to committing to a given tariff exante, that is, before demand is actually realized.

\subsection{Firms}

There are two risk-neutral firms in the market, Firm 1 and Firm 2, producing a single product at a zero marginal cost. Initially, each firm has half of the mass one continuum of consumers.

There is a switching cost for switching from Firm $i$ to Firm $j$, paid by consumers and exogenous. We can think of , for example, as a transaction cost or a contractual switching cost, that is, a monetary cost that consumers would have to pay in case of breaking their contract with a given firm. Under this situation, the switching cost could either be fixed by a regulator in an optimal way, or offered by the firms as part of the initial contract they offer to consumers ${ }^{5}$.

Notice that the switching cost $s_{i}$ gives firms market power, as it locks-in their own consumers. It can, hence, be seen as a way for firms to differentiate their products. Then, the higher the switching costs, the lower the degree of competition in the market.

\footnotetext{
${ }^{4}$ More thorough details on the distribution of consumers' information cost $c$ will be given when presenting the setting for firms.

5 However, while we consider the first interpretation, of $S_{i}$ being set by a regulator, in Section 5 , the second interpretation, $S_{i}$ being part of an initial contract offered by the firms to the consumers, determinant of the way consumers choose between firms and end-up locked in with one of the firms, lies outside the scope of our analysis. As mentioned before, we assume that consumers are already locked-in, half of them being assigned to Firm 1 and the other half to Firm 2.
} 
Price discrimination between Firm's $i$ existent customers (price $P_{i}^{i}$ ) and potential new customers (price $P_{i}^{j}$ ) is possible. Indeed, in this market firms constantly try to attract new customers by offering them not only lower tariffs, but a new phone, free access to the Internet etc.

In addition to posting prices $P_{i}^{i}$ and $P_{i}^{j}$ for the good, each firm is able to costlessly choose the degree of information provision, that is, how high the information cost of its own consumers can be. That is, each firm has the possibility to choose a $c_{i}$ such that the information cost of its own consumers is uniformly distributed between 0 and $c_{i}\left(c \sim U\left[0, c_{i}\right]\right.$ for consumers of Firm $\left.i\right)$, where $c_{i} \in\left[0, c_{\max }\right]$, and $c_{\max } \geq \underline{c}^{6}$. As we said before, represents the time needed by any consumer to become informed. It makes sense to believe that, at least partially, this time is determined by the firm. We might have all the firms in the market sending standardized bills by regular mail to all their consumers, or on the contrary, we might have a situation where the consumers have to connect to the Internet, sign-up for an account and ask to be sent the bill at their house (or download it from the Internet). Clearly, the second situation is more costly in terms of time spent. Also, they might make all their tariffs similar, by just posting the price of a call per minute and the price of a message, or they could disguise tariffs in different ways, with special phone, Internet offers etc. It is obvious that it is easier to compare tariffs in the first case.

Following notation by Bar-Isaac, Caruana and Cuñat (2010), we will refer to transparency when a given firm makes it costless for all its consumers to learn their valuation $\left(c_{i}=0\right)$, and to opacity when the firm makes it as costly as possible $\left(c_{i}=c_{\max }\right)$. Introducing costs to the firms for choosing different degrees of information provision seems a natural extension, which shall be analyzed in Section 6. We motivate this by means of the fact that is not always easy for firms to make information costly. Generally, there are certain laws that mobile telephone firms have to respect. Bills must not be too different from one firm to another or from one tariff to another (a certain standard must be followed). Also, tariffs must state some minimum information, on price per minute etc. Not fulfilling these minimum information requirements might lead to the imposition of a fine, and this determines a cost of "hiding" information.

\subsection{Timing}

In our baseline model, timing is as follows. In the first place, firms costlessly choose the degree of information provision for their own consumers, $c_{1}$ and $c_{2}$. Secondly, firms post both prices for their own consumers, $P_{1}^{1}$ and $P_{2}^{2}$, and "special prices" to attract consumers from the other firm, $P_{1}^{2}$ and $P_{2}^{1}$.

${ }^{6}$ Where $c=2(1-\alpha)^{2}(\alpha-m)+m(1-\alpha)$, and is a consequence of the firms' maximization problem. Restricting $c_{\max }$ to be higher than $\underline{c}$ is meant to simplify the exposition, without loss of generality. The main intuitions of the model are robust to this restriction. 
In the last place, consumers from a given firm, $i$, observe prices targeted to them, $P_{i}^{i}$ and $P_{j}^{i}$, their own $c$ and the corresponding switching cost $s_{i}$ and decide whether to become informed or not, whether to buy or not and whether to switch firms or not. Notice that, as mentioned before, in our model buying can be interpreted as committing to a given tariff at, say, the beginning of a month, before knowing the future consumption level. Then, when a certain consumer decides to buy from a firm, he commits to paying the corresponding price before knowing his real valuation, 0 or 1 .

\section{The monopoly case}

To gain intuition, we introduce a somewhat simpler model, in which we have only one firm (hereafter Firm 1 or the monopolist) present in the market, providing the good to all the consumers.

Consequently, timing is as follows. First, Firm 1 costlessly chooses the degree of information provision, $c_{1} \in\left[0, c_{\max }\right]$. Then, Firm 1 posts monopoly price $P_{1}$ for the product $^{7}$. Consumers observe price $P_{1}$ and their own $c$ and decide whether to become informed before making their buying decision, or not. In the last place, consumers decide whether to buy or not.

We proceed to solving the model by backwards induction.

\subsection{Consumers' problem}

We start by analyzing consumers' decision of buying the good. As we mentioned before, consumers can become informed first, and then decide whether to buy the product or not as a function of their real valuation for the product, or they can remain uninformed and decide whether to buy the product or not in this situation. These two cases are fundamentally different. In the first case, rational consumers make no mistake, as they are fully aware of their preferences, while in the second case consumers choose based on beliefs.

Let's look at consumers' decision in these two settings separately.

An informed consumer can be of two types. He can be a low type, with a valuation for the product of 0 . Then, a low type consumer would never be willing to buy.

\footnotetext{
7 Notice that in this case, there is only one price $P_{1}$ of selling to all consumers. In makes no sense to speak about a "special offer" price designated to steal consumers from the other firm, given that Firm 1 is a monopolist.
} 
Also, he can be a high type, with a valuation for the product of 1 . This means that he is willing to buy the product for any price lower than 1 . To make this clearer, the utility for a high type informed consumer, given $P_{1}$, is the following:

$$
U_{H}^{I}\left(P_{1}\right)=\left\{\begin{array}{cl}
1-P_{1} & \text { if he buys } \\
0 & \text { otherwise }
\end{array}\right.
$$

Now, let's look carefully at the decision of an uninformed consumer. An uninformed consumer has an ex-ante expected valuation of $\alpha$ for the good. So apparently, he would be willing to buy uninformed at any $P_{i} \leq \alpha$. However, due to riskaversion, remaining uninformed leads to a loss of utility $m$. Then, the expected utility of buying the good uninformed will be the following:

$$
U^{N I}\left(P_{1}\right)=\left\{\begin{array}{cl}
(\alpha-m)-P_{1} & \text { if he buys } \\
0 & \text { otherwise }
\end{array}\right.
$$

So an uninformed consumer would be willing to buy at any price lower than $\alpha-m$. Having seen this, we can proceed by looking into consumers' decision of acquiring information. We can see the dynamics of information acquisition in Figure 1.

On the one hand, becoming informed increases surplus for consumers, as it eliminates the possibility of making a mistake (for example, low types buying uninformed based on ex-ante expected valuation) and, moreover, it avoids losing part of the final utility due to risk-aversion. On the other hand, becoming informed implies a cost $c$, heterogeneous among consumers as mentioned in the description of the model. Then, consumers with a high information cost $\mathrm{c}$ might prefer to remain uninformed.

In any case, for a consumer to decide whether to become informed or not, he must first decide whether he would buy the product uninformed or not. That is, a consumer must fully understand his reservation utility. In particular, we must distinguish

\section{FIGURE 1}

\section{THE DECISION TREE FOR THE MONOPOLY CASE}

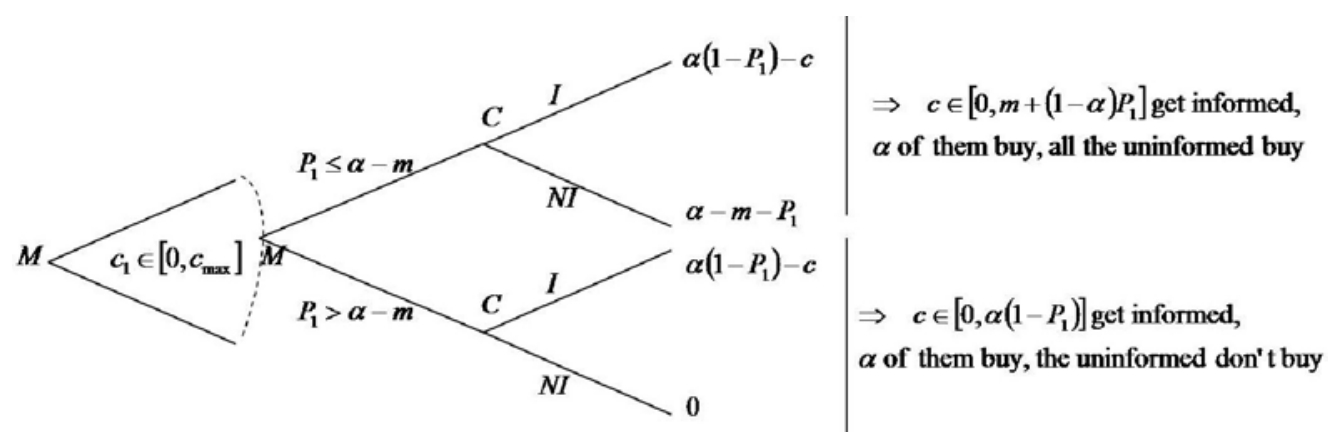


between two cases. According to equation [3.2], when $P_{1} \leq \alpha-m$, consumers would be willing to buy uninformed. Then their reservation utility from remaining uninformed is $U^{N I}\left(P_{1} / P_{1} \leq \alpha-m\right)=(\alpha-m)-P_{1}$. In this case, a consumer will become informed if his utility from doing so is higher than his utility from remaining uninformed $\left(U^{I}\left(P_{1} / P_{1} \leq \alpha-m\right) \geq U^{N I}\left(P_{1} / P_{1} \leq \alpha-m\right)\right)$, that is, if:

$$
\alpha\left(1-P_{1}\right)+(1-\alpha) 0-c \geq(\alpha-m)-P_{1} \Rightarrow c \leq \overline{c_{L}}=m+(1-\alpha) P_{1}
$$

where the left-hand side of the first inequality represents the fact that, with probability $\alpha$, a consumer becoming informed will be a high type and value the good 1 , and with probability $1-\alpha$, a consumer becoming informed will be a low type, value the good 0 and decide not to buy. $\overline{c_{L}}$ represents the indifferent consumer between becoming informed or not, when $P_{1} \leq \alpha-m$. Hence, $\frac{\overline{c_{L}}}{c_{1}}$ represents the proportion of consumers becoming informed in this setting.

Instead, for $1>P_{1}>\alpha-m$, consumers would not buy uninformed (equation [3.2]). Then their reservation utility from remaining uninformed is $U^{N I}\left(P_{1} / P_{1}>\alpha-m\right)=0$. Again, a consumer will become informed if his utility from doing so is higher than the one from remaining uninformed $\left(U^{I}\left(P_{1} / P_{1}>\alpha-m\right) \geq U^{N I}\left(P_{1} / P_{1}>\alpha-m\right)\right)$, that
is, if:

$$
\alpha\left(1-P_{1}\right)+(1-\alpha) 0-c \geq 0 \Rightarrow c \leq \overline{c_{H}}=\alpha\left(1-P_{1}\right)
$$

where $\overline{c_{H}}$ represents the indifferent consumer between becoming informed or not, when $P_{1}>\alpha-m$. Consequently, $\frac{\overline{c_{H}}}{c_{1}}$ represents the proportion of consumers becoming informed in this setting.

Summarizing, when $P_{1} \leq \alpha-m$, all consumers with $c \in\left[0, \overline{c_{L}}\right]$ will acquire information on their type, high types will buy the product and low types will not. Also, all consumers remaining uninformed, that is, consumers with $c \in\left[\overline{c_{L}}, c_{1}\right]$, will buy the product. Instead, when $P_{1}>\alpha-m$, all consumers with $c \in\left[0, \overline{c_{H}}\right]$ will acquire information on their type, high types will buy the product and low types will not. However, in this case uninformed consumers, that is, consumers with $c \in\left[\overline{c_{H}}, c_{1}\right]$, will not buy the good.

To make this clearer, the following expression summarizes demand for the monopolist, as a function of the price set $P_{1}$ and of the degree of information provision, $c_{1}$ : 


$$
D\left(P_{1}, c_{1}\right)=\left\{\begin{array}{ccc}
1-(1-\alpha) \frac{\overline{c_{L}}}{c_{1}} & \text { if } & P_{1} \leq \alpha-m \\
\alpha \frac{\overline{c_{H}}}{c_{1}} & \text { if } & \alpha-m<P_{1} \leq 1 \\
0 & \text { if } & P_{1}>1
\end{array}\right.
$$

\subsection{Firm's problem}

With these preliminary results, we can now analyze Firm 1's price setting decision. Consumers' problem distinguishes two main options for the firm, concerning the monopoly price $P_{1}$. In particular, Firm 1 can set either $P_{1} \leq \alpha-m$, or $P_{1}>\alpha-m$.

Let's look, in the first place, at the case where $P_{1} \leq \alpha-m$. In this situation, and according to equation [3.5], Firm 1 faces the following maximization problem:

$$
\max _{P_{1}, c_{1}} \pi\left(P_{1}, c_{1}\right)=P_{1}\left[1-(1-\alpha) \frac{\overline{c_{L}}}{c_{1}}\right]
$$

The following lemma summarizes Firm 1's optimal strategy for a price $P_{1} \leq \alpha-m$.

Lemma 1. When $P_{1} \leq \alpha-m$, the optimal $c_{1}$ is $c_{1}^{*}=c_{\max }$. It follows that $P_{1}^{*}=\alpha-m$.

In the second place, we look at the case where $P_{1}>\alpha-m$. Again, according to equation [3.5], Firm 1 faces the following maximization problem:

$$
\max _{P_{1}, c_{1}} \pi\left(P_{1}, c_{1}\right)=P_{1}\left[\alpha \frac{\alpha\left(1-P_{1}\right)}{c_{1}}\right]
$$

The following lemma summarizes Firm 1's optimal strategy for a price $P_{1}>\alpha-m$.

Lemma 2. When $P_{1}>\alpha-m$, the optimal $c_{1}$ is $c_{1}^{*}=0$. It follows that $P_{1}^{*}=1$.

Briefly, we discuss the intuitions behind Lemma 1 and Lemma 2.

If $P_{1} \leq \alpha-m$, Firm 1 sells to both uninformed and informed high type consumers. Out of all the informed consumers, a proportion $1-\alpha$ will always be low type. Then, as more consumers become informed (as $c_{1}$ decreases), more consumers learn that their type is low and their valuation for the product is 0 . Hence, more consumers decide not to buy. Also, as more consumers become informed, more consumers learn that their type is high and their valuation for the product is 1 , so they decide to buy. But these consumers would have been willing to buy the product uninformed. Consequently, as $c_{1}$ decreases, for any given price level $P_{1}$ there is a loss in demand for Firm 1 due to the low types learning that their valuation is 0 , and no gain in demand due to the high types. Firm 1 has incentives to make information as costly as possible, in order to avoid consumers becoming informed. In this setting, profits for Firm 1 are maximized at $c_{1}^{*}=c_{\max }$. Opacity is optimal. 
In turn, when $P_{1}>\alpha-m$, Firm 1 sells only to informed high type consumers. Out of all the informed consumers, a proportion $\alpha$ will always be high type. Then, as more consumers become informed (as $c_{1}$ decreases), more consumers learn that their type is high and their valuation for the product is 1 . Hence, more consumers become willing to buy, so demand for Firm 1 decreases with $c_{1}$ for any given price level $P_{1}$. Firm 1 has incentives to make information available to all consumers. In this setting, profits for Firm 1 are maximized at $c_{1}^{*}=0$. Transparency is optimal.

We notice that results from Lemmas 1 and 2 are similar to the ones stated by Johnson and Myatt (2006), as detailed in the introduction of this paper, and more thoroughly, in Section 7. In particular, the monopolist in our model will either prefer to make information free in order to supply a maximum level of information to its consumers, or it will prefer to make information as costly as possible in order to supply a minimum level of information to its consumers. In the first case and as stated in Lemma 2, the product will be bought by high-type informed consumers at a price $P_{1}^{*}=1$, so the marginal's consumer's valuation for the product is 1 , "above average". On the contrary, in the second case and as stated by Lemma 1, the price for the product will be $P_{1}^{*}=\alpha-m$, equal to the marginal consumer's valuation. So in this last case, the marginal consumer's valuation for the product is "below average".

The following proposition summarizes our main result for this section, concerning the monopoly equilibrium price $P_{1}^{*}$ and information cost $c_{1}^{*}$.

Proposition 3. (Monopoly Equilibrium) In equilibrium, we will have $P_{1}^{*}=1$ and $c_{1}^{*}=0$.

We shall now discuss Proposition 3 exhaustively, as part of its proof. The monopoly equilibrium, $c_{1}^{*}=0$ and $P_{1}^{*}=1$, can be understood as selling at a price of 1 to a total demand of $\alpha$ consumers (in equilibrium, all consumers acquire information on their type as it is free to do so, and a proportion are high type and willing to buy). Profits for this case are represented by the striped rectangle in Figure 2.

The equilibrium is quantitatively equivalent to selling to all consumers (demand 1) at a price of $\alpha$, represented by the dash-lined rectangle in Figure 2.

According to Lemma 1 and Lemma 2, we know that the two profit maximizing options for Firm 1 in the monopoly case are either setting $c_{1}^{*}=0$ and $P_{1}^{*}=1$, that we just saw, or setting $c_{1}^{*}=c_{\max }$ and $P_{1}^{*}=\alpha-m$. Profits for this last case are represented by the light grey rectangle in Figure 2 . We notice that this rectangle is smaller than the dash-lined rectangle, equivalent as mentioned to the striped rectangle representing the equilibrium stated by Proposition 3. There are two reasons for this. On one hand, this last option implies selling at a price $P_{1}^{*}=\alpha-m$, which is lower than $\alpha$. On the other hand, even for the case of opacity, we still have a given proportion of consumers (the ones with low $c$ ) becoming informed. With probability $1-\alpha$, these consumers will be low type and will not be willing to buy. So in expectation, demand will be lower than 1 . Then, choosing $c_{1}^{*}=c_{\max }$ and $P_{1}^{*}=\alpha-m$ as opposed 
FIGURE 2

MAXIMIZING PROFIT IN THE MONOPOLY CASE

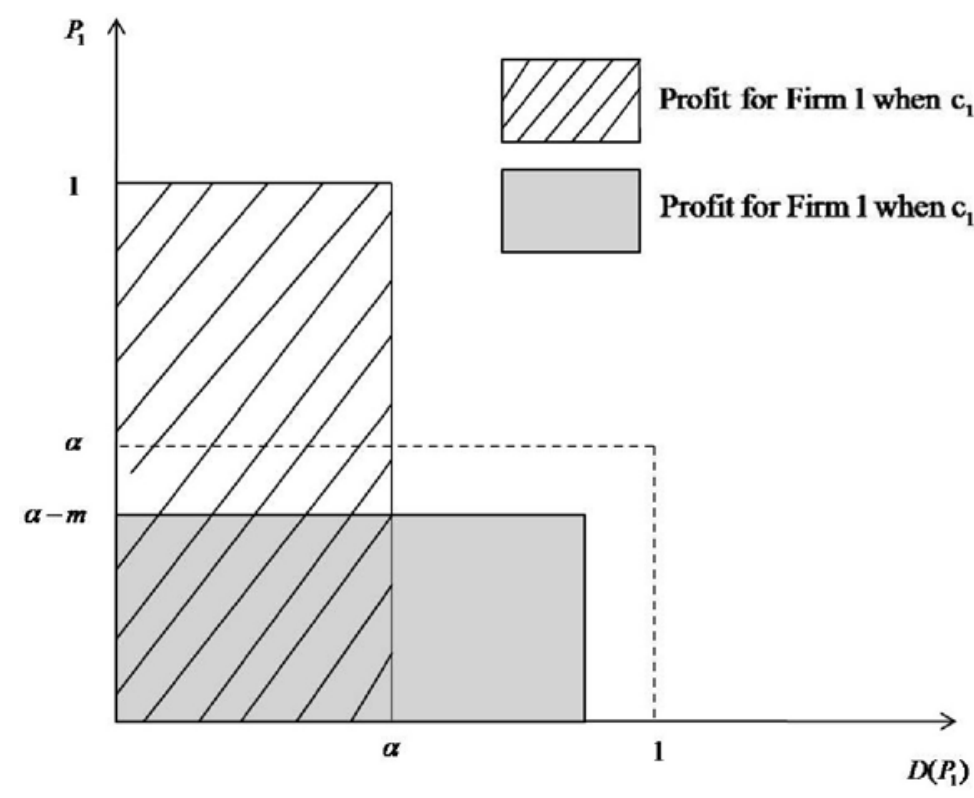

to $c_{1}^{*}=0$ and $P_{1}^{*}=1$ is equivalent to selling at a lower price $(\alpha-m<\alpha)$ to fewer consumers $\left(D\left(\alpha-m, c_{\max }\right)<1\right)$. This cannot be profit maximizing. Hence, the equilibrium will be $c_{1}^{*}=0$ and $P_{1}^{*}=1$.

The intuition behind this result is given by the fact that setting $c_{1}^{*}=0$ and $P_{1}^{*}=1$, as opposed to $c_{1}^{*}=c_{\max }$ and price $P_{1}^{*}=\alpha-m$, leads to all consumers acquiring information on their type. This makes the high types be fully aware of their high valuation of the product, which allows the monopolist to fully exploit them and charge a maximum price of $P_{1}^{*}=1$. However, this comes at a cost, as setting $c_{1}^{*}=c_{\max }$ and price $P_{1}^{*}=\alpha-m$ would instead lead to selling to almost all consumers (uninformed in this case, both high types and low types), as opposed to a proportion of them as in the first case. Demand would then be higher. Nevertheless, for reasons stated above, the first effect dominates the second and Firm 1 prefers selling only to the small niche of high type consumers, but extracting their whole surplus.

\section{The duopoly case}

We are now in a position to analyze how our previous results differ with the existence of competition. In this new section, we will analyze the duopoly case, where 
we have both firms in the market, Firm 1 and Firm 2. In this situation, as mentioned above, each firm has half of the mass one continuum of consumers initially. There is a switching cost $s_{i}$ for switching from Firm i to Firm $\mathrm{j}$, paid by consumers. Timing is as presented in Section 2.

Notice that due to price discrimination being possible, existing customers of Firm 1 and existing customers of Firm 2 represent separate (symmetrical) markets. Without loss of generality, we can analyze only Firm's 1 existent customers: Firm 1 sets a price $P_{1}^{1}$ designated to keep its own customers, and Firm 2 tries to steal customers from Firm 1 at a price $P_{2}^{1}$.

Again, we proceed to solving the model by backwards induction.

\subsection{Consumer's problem}

We start by analyzing a consumer's decision of switching firms. In a similar way to the monopoly case, let's distinguish between the decision of switching firms for informed and uninformed consumers.

As we said before, an informed consumer can be of two types. If he is a high type, his valuation for the good is equal to 1 . Hence, the utility that a high type informed consumer derives from buying from Firm 1 will be, as in the monopoly case,

$$
U_{H}^{I}\left(P_{1}^{1}\right)= \begin{cases}1-P_{1}^{1} & \text { if he buys } \\ 0 & \text { otherwise }\end{cases}
$$

while the utility that a high type informed consumer derives from switching firms and buying from Firm 2 will be

$$
U_{H}^{I}\left(P_{2}^{1}\right)= \begin{cases}1-P_{2}^{1}-s_{1} & \text { if he buys } \\ 0 & \text { otherwise }\end{cases}
$$

Then, a high type informed consumer will switch firms if two conditions are satisfied. In the first place, he must be willing to buy. In the second place, the utility that he derives from switching firms must be higher than the utility of remaining with Firm $1\left(U_{H}^{I}\left(P_{1}^{1}\right)<U_{H}^{I}\left(P_{2}^{1}\right)\right)$, that is, if

$$
1-P_{1}^{1}<1-P_{2}^{1}-s_{1} \Rightarrow s_{1}<P_{1}^{1}-P_{2}^{1}
$$

Given equation [4.3], a high type informed consumer will switch firms if $P_{1}^{1}>P_{2}^{1}+s_{1}$. For simplicity, we assume that if a consumer is indifferent between remaining with Firm 1 and switching firms, he will choose not to switch firms.

On the other hand, a low type informed consumer will not be willing to buy from any of the two firms, for any level of positive price. In this case, switching firms 
(and incurring $s_{1}$ ) is pointless as the consumer derives no utility whatsoever from this action. Hence, a low type informed consumer will never switch firms.

Now, let's look at the decision to switch firms of an uninformed consumer. The utility that the consumer derives from buying from Firm 1 is, in a similar way to the monopoly case,

$$
(\alpha-m)-P_{1}^{1} \geq 0,(\forall) P_{1}^{1} \leq \alpha-m
$$

while the utility that he derives if he switches firms and buys from Firm 2 is

$$
(\alpha-m)-P_{2}^{1}-s_{1} \geq 0,(\forall) P_{2}^{1} \leq(\alpha-m)-s_{1}
$$

Then, an uninformed consumer will switch firms if two conditions are satisfied. In the first place, he must be willing to buy. In the second place, the utility that he derives from switching firms must be higher than the utility of remaining with Firm $1\left(U^{N I}\left(P_{1}^{1}\right)<U^{N I}\left(P_{2}^{1}\right)\right)$, that is, if

$$
U^{N I}\left(P_{1}^{1}\right)<U^{N I}\left(P_{2}^{1}\right) \Rightarrow\left\{\begin{array}{cl}
(\alpha-m)-P_{1}^{1}<(\alpha-m)-P_{2}^{1}-s_{1} & \text { if } P_{1}^{1} \leq \alpha-m, P_{2}^{1} \leq(\alpha-m)-s_{1} \\
0<(\alpha-m)-P_{2}^{1}-s_{1} & \text { if } P_{1}^{1}>\alpha-m, P_{2}^{1} \leq(\alpha-m)-s_{1}
\end{array}\right.
$$

This is equivalent to:

$$
U^{N I}\left(P_{1}^{1}\right)<U^{N I}\left(P_{2}^{1}\right) \Rightarrow\left\{\begin{array}{cl}
s_{1}<P_{1}^{1}-P_{2}^{1} & \text { if } P_{1}^{1} \leq \alpha-m, P_{2}^{1} \leq(\alpha-m)-s_{1} \\
s_{1}<(\alpha-m)-P_{2}^{1} & \text { if } P_{1}^{1}>\alpha-m, P_{2}^{1} \leq(\alpha-m)-s_{1}
\end{array}\right.
$$

In light of equations [4.3] and [4.7], we state the following:

Lemma 4. When $P_{2}^{1}+s_{1}<P_{1}^{1}$, both informed high-type and uninformed consumers (if they buy) will switch firms.

\subsection{Firm's problem}

Lemma 5 partially states the equilibrium strategy for Firm 1, and fully states the equilibrium strategy for Firm 2.

Lemma 5. In equilibrium, we will have $P_{1}^{1} \leq s_{1}$ and $P_{2}^{1}=0$. No consumer will switch firms.

Proof. Let's assume, on the contrary, that in equilibrium Firm 1 sets a price higher than the switching cost, $P_{1}^{1}>s_{1}$. Then, Firm 2 can set a price $P_{2}^{1}<P_{1}^{1}-s_{1}$, in particular, it can set a price $P_{2}^{1}=P_{1}^{1}-s_{1}-\varepsilon$, and $P_{2}^{1} \geq 0$. But then we will have $s_{1}<P_{1}^{1}-P_{2}^{2}$, and we saw that this was a sufficient condition for both uninformed (if 
they buy) and high type informed consumers to switch firms. Hence, demand for Firm 1, and consequently, profits, will be 0 . But in this situation, Firm 1 has incentives to lower its price to $P_{1}^{1}<P_{2}^{1}+s_{1}$. This situation will go on until a limit situation is reached, in particular, until Firm 2 cannot lower its price anymore. That is, $P_{2}^{1}=0$. Consequently, Firm 1 will set a price $P_{1}^{1} \leq s_{1}$ in order to avoid losing consumers ${ }^{8}$.

The intuition behind this result is that in the presence of competition, and according to Lemma 4, firms fight for all consumers that matter (all consumers that are willing to buy the product). In equilibrium either all consumers switch firms, or none does. In this setting, giving up one consumer implies giving up the whole demand, that is, it implies zero profits. That is the reason why competition is so harsh among the two firms, that it drives down the price of Firm 2 to zero. In the absence of switching costs, we would have the Bertrand competition outcome. Both firms would set prices equal to their marginal cost, that is, equal to zero.

In light of the above, we can proceed with solving the duopoly equilibrium. In particular, several aspects must be taken into account.

In the first place, as in equilibrium no consumer will switch firms, we can completely exclude Firm 2 from our analysis. That is, in order to analyze the equilibrium we, again, need to analyze the optimal strategy for Firm 1 (optimal information cost $c_{1}$ and optimal price $P_{1}^{1}$ ), as in the monopoly case. The only difference being that now, Firm 1's price is restricted by the switching cost $s_{1}$.

In the second place, the degree of competition in the market, defined by the switching cost, will affect the equilibrium outcome ${ }^{9}$.

The first aspect mentioned above has the direct implication that all the analysis that we performed in Section 3 is still valid. In more detail, for a price $P_{1}^{1} \leq \alpha-m$, the optimal degree of information provision will be the minimum one, $c_{1}^{*}=c_{\max }$. Moreover, for a price $P_{1}^{1}>\alpha-m$, transparency will be optimal for Firm 1. That is, $c_{1}^{*}=0$. Also, Firm 1 will consider the two options that we saw before: setting either a price $P_{1}^{1}=\alpha-m$, complemented by minimum information provision, or a price $P_{1}^{1}=1$, complemented by transparency. Again, Firm 1 would exhibit a clear preference for the second case. However, Firm 1's price is now restricted by the switching cost, $s_{1}$.

This brings us to the second aspect mentioned above. In particular, when the switching cost is low (i.e. $s_{i} \leq \alpha-m$ ), it is straightforward that the firm has no choice but to set a price $P_{1}^{1} \leq s_{1} \leq \alpha-m$, that is, $P_{1}^{1} \leq \alpha-m$. But we know that in this situation, opacity is optimal and in equilibrium we shall clearly have $P_{1}^{1^{*}}=s_{1}$ and $c_{1}^{*}=c_{\max }$.

${ }^{8}$ Firm 1 will set $P_{1}^{1}=s_{1}$ (the maximum possible) unless it is optimal, as a result of the firm's maximization problem, to set some price $P_{1}^{1}<s_{1}$.

${ }^{9}$ The higher the switching cost, the less is Firm 1's price level restricted, in particular a switching cost of 1 or higher would be equivalent to the monopoly case, while a switching cost of 0 would be equivalent to perfect competition. 
Nevertheless, it might be that competition is not that harsh, in particular we might have $s_{1}>\alpha-m$. Not being as restricted by competition as before, Firm 1 may now choose between two possible optimal strategies. It can either set a price $P_{1}^{1^{*}} \leq s_{1} \leq \alpha-m$, complemented by a minimum degree of information provision $c_{1}^{*}=c_{\max }$, or it can set a somewhat higher price, $P_{1}^{1^{*}}=s_{1}$, complemented by a complete information situation, $c_{1}^{*}=0$.

It is not obvious that the equivalent of the monopoly equilibrium, that is, a high price complemented by complete information, will be optimal.

Consequently, the following proposition summarizes the equilibrium outcome for the duopoly case.

Proposition 6. (Duopoly equilibrium) There ( $\exists$ ) an $\overline{s_{1}}$ s.t.:

- When $s_{1} \leq \overline{s_{1}}$, the equilibrium is $P_{1}^{1^{*}}=\min \left\{s_{1}, \alpha-m\right\}$ and $c_{1}^{*}=c_{\max }$.

- When $s_{1}>\overline{s_{1}}$, the equilibrium is $P_{1}^{1^{*}}=\min \left\{s_{1}, 1\right\}$ and $c_{1}^{*}=0$.

Briefly, we discuss the intuition behind Proposition $6^{10}$. As we said, when $s_{1} \leq \alpha-m$, the result is straightforward as the only option for Firm 1 is to set a price $P_{1}^{1^{*}}=s_{1}$, complemented by minimum information provision $c_{1}^{*}=c_{\max }$. But when $s_{1}>\alpha-m$, Firm 1 has the possibility to either set a price $P_{1}^{1^{*}}=\alpha-m$, complemented by $c_{1}^{*}=c_{\max }$, or set a price $P_{1}^{1^{*}}=s_{1}>\alpha-m$, and complement it with complete information, $c_{1}^{*}=0$. In the monopoly case, transparency was optimal.

As we said, the monopoly case represents a trade-off between two main effects. On the one hand, providing information to all consumers leads to a loss in demand, as a proportion $1-\alpha$ of them learn that their valuation for the product is 0 . On the other hand, the monopolist is able to fully exploit the proportion $\alpha$ that values the product 1 . This second effect dominates the first one.

However, in the duopoly case Firm 1 cannot fully exploit the high types at a price of 1 , as price is restricted by the degree of competition in the market, in particular, by the switching cost $s_{1}$. Then, while the first effect is equally strong in competition, the second one is now weaker, as extracting the whole surplus from the high types is no longer possible. As a consequence, it might be that the first effect dominates the second one, and Firm 1 prefers selling at a somewhat lower price, $P_{1}^{1^{*}}=\alpha-m$, but to a higher proportion of consumers (both informed high types and uninformed).

In particular, it depends on how harsh competition is. If $s_{1}$ is close enough to 1 , Firm 1 can still sufficiently exploit the high types and the second effect dominates. However, as $s_{1}$ gets closer to $\alpha-m$, the increase in price from informing all consu-

$10 \overline{s_{1}}$ in Proposition 6 is a consequence of the firm's maximization problem, and its value is

$$
\overline{s_{1}}=\max \left\{\alpha-m,(\alpha-m) \frac{1}{\alpha}\left[1-(1-\alpha) \frac{m+(1-\alpha)(\alpha-m)}{c_{\max }}\right]\right\} .
$$


mers is insignificant, while the loss in demand is high. This inclines the balance in favour of the first effect, and makes the firm prefer to sell at a price $P_{1}^{1^{*}}=\alpha-m$ to a high demand.

\section{Welfare considerations}

In this section of the paper, we shall try to understand the implications of our analysis so far (the monopoly and duopoly case) on social welfare maximization.

Here, social welfare will be composed by consumer surplus (surplus of informed high type consumers, and surplus of uninformed consumers if they buy), plus firms' profits. Notice, however, that Firm 2 sets a price $P_{2}^{1}=0$ and faces zero demand, so its profit from consumers that originally bought from Firm 1 will be zero. It can be excluded from the social welfare function.

In the monopoly case, we have seen that the optimal strategy for the firm is setting a maximum price, $P_{1}^{*}=1$, complemented by transparency, that is, $c_{1}^{*}=0$. As a consequence, all consumers acquire information on their type, and they costlessly do so. This has two clear positive effects in what social welfare is concerned. On the one hand, even if the whole mass of consumers gets informed, no information cost is actually incurred. This is due to the fact that in equilibrium, information is free. On the other hand, the fact that in equilibrium, all consumers end up learning their type implies that no consumer buys uninformed. This, again, is beneficial for social welfare as it saves on risk-aversion costs (no consumer loses $\mathrm{m}$ from his utility). Both these effects positively repercute on consumer surplus, as it is the final consumer who would end up paying information and risk-aversion costs, in a costly information situation.

However, we must not forget that in the monopoly case, while indeed information is complete, the final price is equal to 1 . That is, the monopolist extracts the whole surplus from consumers. So even if the first best is achieved, as no information or risk-aversion costs are incurred and all consumers that are supposed to buy do so, consumer surplus is zero.

Let's now analyze the duopoly case. As mentioned above, a low degree of competition, represented by a high switching cost $s_{1}$ (higher than $\overline{s_{1}}$ ), will lead to an equilibrium similar to the monopoly one. That is, we will have $P_{1}^{1^{*}}=\min \left\{s_{1}, 1\right\}$ and complete information $c_{1}^{*}=0$. In equilibrium, all consumers will costlessly become informed. As a consequence, no consumer will incur in risk-aversion costs, $m$. Only high type consumers will buy the good.

Then consumer surplus will be

$$
C S\left(s_{1} / s_{1}>\bar{s}_{1}\right)=\alpha\left(1-P_{1}^{1^{*}}\right)
$$

where $\alpha$ represents the proportion of high type consumers, that is, consumers who are willing to buy, and $1-P_{1}^{1^{*}}$ represents surplus for each one of these consumers. 
Firm 1's profits will be

$$
\pi_{1}\left(s_{1} / s_{1}>\bar{s}_{1}\right)=\alpha P_{1}^{1^{*}}
$$

We start with the simplest case, that is, we give equal weights to consumers and firms in the social welfare function. In this situation, social welfare will be

$$
W\left(s_{1} / s_{1}>\overline{s_{1}}\right)=\alpha
$$

We notice that as long as the switching cost is high enough (higher than $\overline{s_{1}}$ ), social welfare in this setting does not depend on it. Also, in total surplus terms this result is equivalent to the monopoly outcome, so it is efficient.

However, when competition is harsh, that is, for low values of $s_{1}$ (lower than $\overline{s_{1}}$ ), the duopoly equilibrium will be given by $P_{1}^{1^{*}}=\min \left\{s_{1}, \alpha-m\right\}$ and $c_{1}^{*}=c_{\max }$. We have two negative effects. On the one hand, some consumers, the ones with low $c$ 's, will acquire information on their type, but they will do so at a cost, and on the other hand, there will be some consumers remaining uninformed and buying. These last ones will incur in risk-aversion costs, $\mathrm{m}$. In the last place, if we look at the "who buys" criteria, all consumers that should buy do so, so efficiency is unaffected from this point of view ${ }^{11}$.

In conclusion, with a high degree of competition in the market, the duopoly outcome is inefficient (social welfare is lower than $\alpha$, achieved, as we saw, for low degrees of competition in the market).

In light of the above, it makes sense to believe that regulation to find the optimal switching cost is needed in order to improve social welfare. The following proposition summarizes our results for this section:

Proposition 7. (Optimal switching cost) $(\forall) s_{1} \in\left[\overline{s_{1}}, \infty\right]$ is optimal.

The intuition behind Proposition 7 is straightforward. Setting the switching cost high enough allows Firm 1 to achieve the monopolistic outcome even under a competition situation by making it impossible for consumers to switch firms. However, under the assumption that consumers and firms have the same weight in the social welfare function, the monopolistic outcome coincides with the first-best, hence, this is optimal.

Finally, we also analyze the situation in which consumers have more weight than firms in the social welfare function. Again, there are two possibilities given by the optimal decision of the regulator. We might have a complete information situation,

\footnotetext{
11 One might think that having consumers buying uninformed could be welfare reducing, as a proportion $1-\alpha$ of them are low types that do not value the product. However, in our model marginal costs of production are 0 , so producing for consumers that do not value the good does not affect efficiency (no useless production costs are incurred). In what the price paid by these consumers is concerned, in this setting it is just a transfer from consumers to firm, so it does not affect social welfare.
} 
complemented by a low level of competition in the market, hence a high price charged to consumers, or on the contrary, we might have a situation where information is costly, but the level of competition is high and consumers end up paying a low price.

We start by assuming that the regulator, or social planner, sets a switching cost $s_{1}$ higher than $\overline{s_{1}}$, hence the duopoly equilibrium will be $P_{1}^{1^{*}}=\min \left\{s_{1}, 1\right\}$ and $c_{1}^{*}=0$.

In this situation, social welfare is given by

$$
W\left(s_{1} / s_{1}>\bar{s}_{1}\right)=\gamma\left[\alpha\left(1-P_{1}^{1^{*}}\right)\right]+\alpha P_{1}^{1^{*}}
$$

where $\gamma>1$ is the weight given to consumers in the social welfare function.

The optimal switching cost under these conditions is

$$
s_{1}^{*}=\overline{s_{1}}
$$

The intuition behind this result is given by the fact that any switching cost higher than the stated $s_{1}^{*}$ would be equally efficient in terms of information provision (no information or risk-aversion cost would be incurred), but it would imply consumers having to pay a higher price for the product. Given that consumers have a higher weight in the social welfare function, this cannot be welfare maximizing.

In the second place, we assume that the regulator sets a switching cost $s_{1}$ lower than $\overline{s_{1}}$. The duopoly equilibrium will now be $P_{1}^{1^{*}}=\min \left\{s_{1}, \alpha-m\right\}$ and $c_{1}^{*}=c_{\max }$.

Consequently, social welfare is given by

$$
\begin{aligned}
W\left(s_{1} / s_{1} \leq \bar{s}_{1}\right) & =\gamma\left[\alpha\left(1-P_{1}^{1^{*}}\right) \frac{m+(1-\alpha) P_{1}^{1^{*}}}{c_{\max }}-\frac{1}{2}\left[m+(1-\alpha) P_{1}^{1^{*}}\right]^{2}\right] \\
& +\gamma\left[1-\frac{m+(1-\alpha) P_{1}^{1^{*}}}{c_{\max }}\right]\left[(\alpha-m)-P_{1}^{1^{*}}\right] \\
& +P_{1}^{1^{*}}\left[1-(1-\alpha) \frac{m+(1-\alpha) P_{1}^{1^{*}}}{c_{\max }}\right]
\end{aligned}
$$

and the optimal switching cost in this situation is given by

$$
s_{1}^{*}=\max \left\{0, \frac{m[(2 \gamma-1)(1-\alpha)]-c_{\max }[\gamma m(1-\alpha)+\gamma-1]}{(1-\alpha)\left[\gamma(1-\alpha) c_{\max }-2(\gamma-1)(1-\alpha)\right]}\right\}
$$


However, as opposed to the case where consumers and firms have equal weights in the social welfare function, here which case is optimal is not straightforward anymore. When $\gamma=1$, the price paid by consumers for the product does not affect social welfare. It can be seen as a transfer from consumers to the firm. Then, the way to maximize social welfare is, as mentioned before, by making sure that no information or risk-aversion costs are incurred, that is, for high values of the switching cost $s_{1}$.

Nevertheless, under this new specification, the fact that consumers pay a too high price matters, in particular, the higher the price, the lower social welfare will be, if we forget about other possible effects. The regulator has reasons to decrease the switching cost.

Figure 3 shows how the optimal switching cost $s_{1}^{*}$ changes with $c_{\max }$, that is, with how costly information can become. The first part of the graph (where the optimal switching cost decreases with $c_{\max }$ ) represents values for $c_{\max }$ where it is optimal to set $s_{1}^{*} \leq \overline{s_{1}}$, with the direct consequence that in equilibrium we will have a situation of opacity, $c_{1}^{*}=c_{\max }$ and the corresponding low price. The optimal in this case would be the one stated in equation [5.7].

The second part of the graph (where the optimal switching cost increases with $c_{\max }$ ) represents just the opposite. Values for $c_{\max }$ where it is optimal to set a $s_{1}^{*}>s$. In equilibrium we will have a situation of transparency, $c_{1}^{*}=0$ and the corresponding high price $P_{1}^{1^{*}}=s_{1}^{*}$, where $s_{1}^{*}$ is determined by equation [5.5].

We notice that when $c_{\max }$ is small, it is optimal to set a low switching cost even if this provides the firm with incentives for "hiding" information. The reason is that as information cannot, in any case, be too costly, the two negative effects mentioned

FIGURE 3

OPTIMAL SWITCHING COST $s_{1}$ AS A FUNCTION OF $c_{\text {max }}$ FOR $\gamma>1$

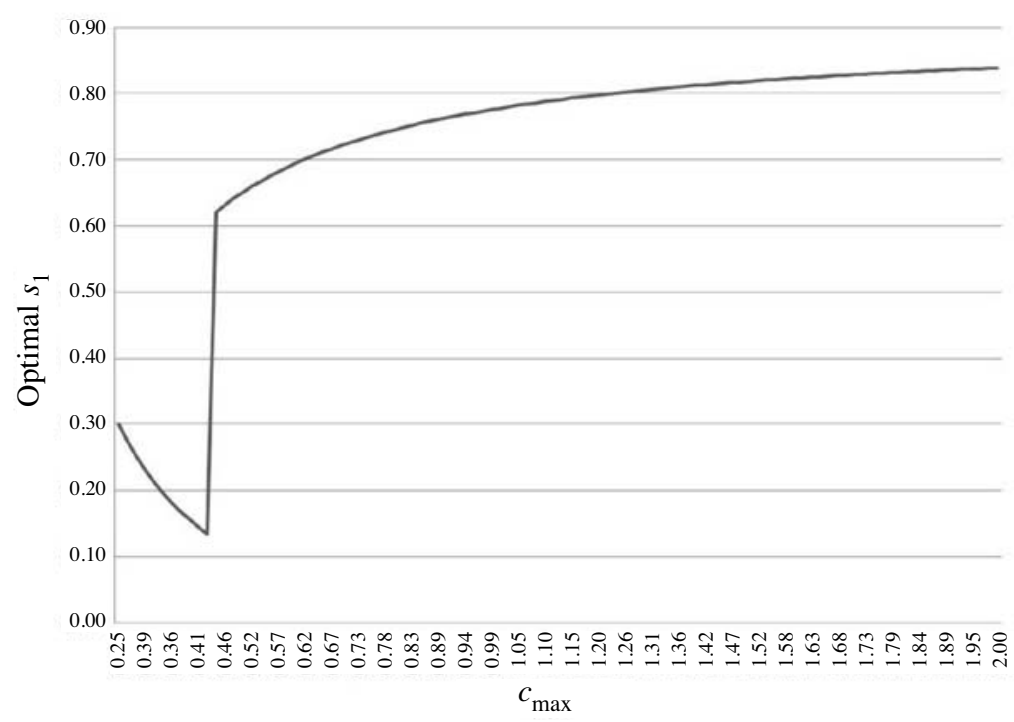


before (consumers paying both information and risk-aversion costs) are small. Hence, the third effect, which is the fact that caring more for consumers in the social welfare function makes it optimal for them to pay a low price, dominates. Also, in this area the optimal switching cost decreases with $c_{\max }$. The reason is that, as $c_{\max }$ increases, it becomes more costly to acquire information. To avoid consumers becoming informed, the optimal action is to reduce the switching cost, i.e., the price they pay, in order to give them less incentives for it.

As $c_{\max }$ increases, the two negative effects from setting a switching cost too low become stronger. Information becomes too costly, so too high costs will be paid for it. Also, more consumers will remain uninformed and pay the cost of risk-aversion. When these two effects start dominating the positive one (consumers paying a low price for the product), it becomes optimal to set a high switching cost, $s_{1}^{*}=\overline{s_{1}}$. We notice that in this area the optimal switching cost increases with $c_{\max }$ (that is, $\overline{s_{1}}$ increases with $\left.c_{\max }\right)$. The intuition behind this is that, as $c_{\max }$ increases, making information costly at a low price becomes more attractive for the firm, as less consumers become informed (demand is higher). In order to compensate for this effect, the firm must be allowed to set a higher price and extract more surplus from consumers in the transparency situation.

\section{The duopoly case with costly information concealing}

So far we have assumed that firms could costlessly choose the degree of information provision. However, it makes sense to believe that this might not be the case in the mobile telephone market. As we mentioned before, there might exist some minimum requirements of information. For example, a law that makes standardized bills compulsory, or the obligation to post tariffs in a similar way (call cost per minute, SMS cost etc.). In this situation, not respecting requirements, and making information too costly, might bring with certain probability a fine. Moreover, in real world terms, firms must be able to hide information in a smart way. Consumers must not perfectly understand and interpret all the existent tariffs, but they must still find them attractive. Being able to intelligently "hide" information probably implies at least an opportunity cost of time. Summarizing, there are several reasons for which lack of information provision might be costly.

In light of the above, we will now extend our existent framework in order to explore the potential effects of introducing a cost for "hiding" information. Our extended model will build on the description of the baseline model, but will incorporate a new assumption. It will now be costly for the firms to set an information cost different than 0 . The cost function for information concealing will take the form $C\left(c_{i}\right)=a+b c_{i}$.

A direct implication of maintaining the main assumptions of the baseline model is the fact that we can rely on our equilibrium analysis performed in Sections 2 and 3 . 
In the first place, the monopoly case remains unchanged. The reason for this is that in the monopoly equilibrium, the firm had incentives to provide complete information, that is, $c_{1}^{*}$, even when hiding information was free. It is then straightforward that this result will not change under our extended framework, where hiding information is costly.

However, in the duopoly case, results stated in Proposition 6 are no longer valid. The reason is that now Firm 1 has lower incentives to make information costly, as this implies a cost and a decrease in profits.

In particular, we analyze the optimal degree of information provision choice for the firm.

Firm 1 solves the following maximization problem:

$$
\max _{c_{1}} \pi\left(c_{1}\right)=P_{1}^{*^{*}}\left[1-(1-\alpha) \frac{m+(1-\alpha) P_{1}^{1^{*}}}{c_{1}}\right]-a-b c_{1}
$$

where is given by $P_{1}^{1^{*}}=\min \left\{s_{1}, \alpha-m, \frac{c_{1}-m(1-\alpha)}{2(1-\alpha)^{2}}\right\}$.

The following proposition summarizes the optimal information provision strategy for the firm:

Proposition 8. (Optimal degree of information provision with costly information concealing)

There ( $\exists$ ) $a \bar{b}$ such that:

- When $b \leq \bar{b}$ and the switching cost is low enough, the optimal degree of information provision is given by:

$$
c_{1}^{*}=\min \left\{\sqrt{\frac{m(1-\alpha) s_{1}+\left[(1-\alpha) s_{1}\right]^{2}}{b}}, \sqrt{\frac{m(1-\alpha)(\alpha-m)+[(1-\alpha)(\alpha-m)]^{2}}{b}}, c_{\text {max }}\right\}
$$

Under these circumstances, an increase in the risk-aversion cost $m$, an increase in the switching cost $s_{1}$, a decrease in the proportion of high-types in the population, $\alpha$, or a decrease in the cost of hiding information, $b$, lead to an increase in the optimal information cost $c_{1}^{*}$.

- Else, the optimal degree of information provision is given by:

$$
c_{1}^{*}=0
$$

Briefly, we explain the intuition behind the results presented in Proposition 8 . 
When "hiding" information is cheap ( $b$ small, that is, $b \leq \bar{b})$, there are situations in which Firm 1 prefers to make information costly (the optimal degree of information provision is lower than transparency) and sell at a low price to both informed high type and uninformed consumers. However, unless "hiding" information is really cheap, opacity shall not be optimal anymore. Instead, some intermediate degree of information provision will be.

Let's try to understand the comparative statics of the optimal information cost, $c_{1}^{*}$, in this situation. As mentioned in Proposition 8, an increase in the risk-aversion cost $m$, an increase in the switching cost $s_{1}$ or a decrease in the proportion of high types in the population, $\alpha$ have, qualitatively, the same effect on the optimal information $\operatorname{cost} c_{1}^{*}$. In particular, they lead to an increase in $c_{1}^{*}$.

The reason for this is as follows. The higher the risk-aversion coefficient $\mathrm{m}$, the higher is the loss in utility if consumers buy uninformed. This gives incentives to consumers to become informed, which leads to a loss in demand for the firm, as we can see in equation [3.6]. So, even at a cost, the firm has now higher incentives to make information costly, in order to avoid consumers becoming informed.

The logic behind an increase in the switching cost $s_{1}$ is similar. The higher the switching cost, the higher is the price that consumers have to pay for the product. This increases the gravity of their mistake if they buy uninformed and turn out to be a low type. Trying to avoid this situation gives consumers higher incentives to become informed, decreasing the demand for the firm. Hence, the firm wants to increase the information cost in order to decrease the proportion of consumers getting informed.

In the same line of reasoning, a decrease in $\alpha$ decreases the proportion of high types in the population, so increases the probability of committing a mistake when buying uninformed. Again, consumers have higher incentives to become informed. A higher proportion of them will do so, decreasing demand for the firm. To avoid this effect, the firm must make information more costly, even at a cost.

Comparative statics related to the cost of "hiding" information, $b$, are straightforward. The more costly "hiding" information is, the higher the optimal degree of information provision chosen by the firm.

These results are, of course, only valid when the degree of competition in the market is high enough, that is, the switching cost $s_{1}$ is low enough. For high values of the switching cost $s_{1}$, the situation is closer to the monopoly case. The firm can exploit the high-types a lot, if these last ones are informed. Then it prefers transparency and losing some demand (even if making information costly is cheap), in order to be able to extract a great amount of surplus from the high-types.

When, instead, "hiding" information becomes expensive for the firm ( $b$ high, that is, $\left.b>\bar{b}_{1}\right)$, transparency becomes optimal, complemented by some profit maximizing price restricted by the level of competition in the market $\left(P_{1}^{1^{*}} \leq s_{1}\right)$.

The importance of this result is that, even when the level of competition is very high (low $s_{1}$, lower than $\alpha-m$ ), that is, situations in which, in our basic specification, opacity was always optimal, it might be that providing complete information 
becomes optimal if the cost of "hiding" information is high enough. This means that, under this new specification, the first best can be achieved under higher levels of competition in the market, that is, lower levels of the switching cost $s_{1}$. So this might be a way for regulation to improve consumer surplus within a first best setting. However, a full analysis of this issue lies outside the scope of this paper.

\section{Firms' preferences for dispersion under monopoly and competition: A comparison with Johnson and Myatt (2006)}

So far, we looked at our model from the point of view of the mobile telephone market. Indeed, our proposed framework seems a good description of this scenario. However, information provision can also be looked at from an advertising, or product design, point of view. Instead of providing information on a consumer's type, or preferences, firms may provide more or less detailed information about the product that they supply. In that respect, our model is similar to Johnson and Myatt (2006).

Johnson and Myatt propose a new framework for analyzing transformations in demand. In particular, they refer to transformations in demand that stem from changes in the dispersion of consumers' valuation, which lead to rotations of the demand curve, as we can see in Figure 4 ("events" that move density away from the center of the distribution of consumers' valuations $\left(f_{s}(\theta)\right)$ and towards the upper and lower tails result in a clockwise rotation of the distribution function).

FIGURE 4

\section{ROTATIONS OF DEMAND (JOHNSON AND MYATT, 2006)}

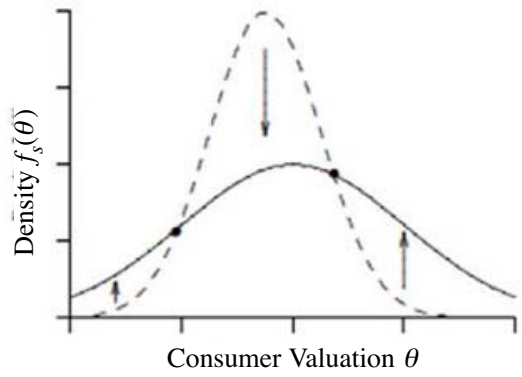

(a) A Spread of the Density Function

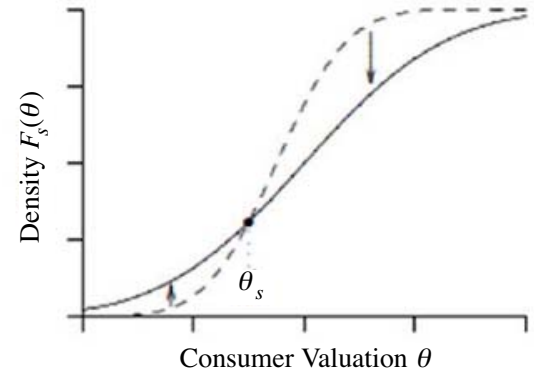

(b) A Rotation of the Distribution Function

Moreover, considering their main application, advertising and information provision, it is innovative in Johnson and Myatt's paper the fact that they suggest a new taxonomy of advertising, distinguishing between real information, which rotates demand, and hype, which shifts demand, as opposed to previous literature, that defi- 
ned only two categories of advertising: persuasive and informative, both with the qualitative effect of shifting the demand curve outward. The authors consider the assumption that advertising will always increase sales restrictive, as having more information on a product might lead to some consumers realizing that the product is not suited for their tastes even as others realize that it is. This motivates demand rotations.

Johnson and Myatt find that monopoly profits are a $U$-shaped function of dispersion (either a maximum or a minimum level of dispersion is optimal). Moreover, whether the monopolist prefers a maximum or a minimum level of dispersion in equilibrium depends on the values of the maximum and minimum levels of dispersion achievable. In the last place, high dispersion is complemented by niche production (the marginal consumer is "above average" in the distribution), while low dispersion is complemented by mass-market supply (the marginal consumer is "below average" in the distribution).

Having stated Johnson and Myatt's main contribution and results, we shall now analyze similarities and differences with our model. As mentioned in the introduction of this paper, Johnson and Myatt focus mainly on monopoly, so starting with our monopoly case seems reasonable for a better comprehension of what we have in common with them. However, in our paper we also thoroughly analyze competition and we shall look into it, trying to understand it within the Johnson and Myatt framework.

Consequently, let us look back at Section 3 of this paper. Timing is as follows. In the first place, the monopolist sets the information cost, $c_{1}$. Secondly, the monopolist sets his price, $P_{1}$, taking into account how costly information is in the market. In the last place, consumers observe their own information cost $c$ and the price set by the monopolist, and decide whether to become informed or not, and whether to buy the product or not.

Given equations [3.4] and [3.5] and Lemma 1 and 2, the proportion of consumers becoming informed is, in the end, a function only of (as a decision variable, not stated by the model). Hence, when the monopolist chooses $c_{1}$, he chooses the proportion of consumers becoming informed. Consequently, he affects the final distribution of consumers' valuations and its dispersion.

To make this clearer, Figure 5A shows the ex-ante distribution of consumers' valuations in our model (before taking any decision). All consumers are ex-ante identical, with a valuation for the product given by $\alpha-m$. On the contrary, Figure $5 \mathrm{C}$ shows the ex-post distribution of consumers' valuations for the product, in equilibrium. All consumers become informed, of them have a valuation of 1 for the product, and $1-\alpha$ a valuation of 0 .

Then, Figure 5B shows how changes in $c_{1}$ affect the ex-post distribution of consumers' valuations. Given equations [3.4] and [3.5] and Lemma 1 and 2, the lower $c_{1}$, the higher the proportion of consumers becoming informed. Then, more consumers (that before valued the product $\alpha-m$ ) learn that their real valuation is either 0 or 1 . This is, then, an "event" that moves density of consumers away from the cen- 
FIGURE 5

\section{CHANGES IN $C_{1}$ LEAD TO CHANGES IN THE DISPERSION OF CONSUMERS' VALUATION}
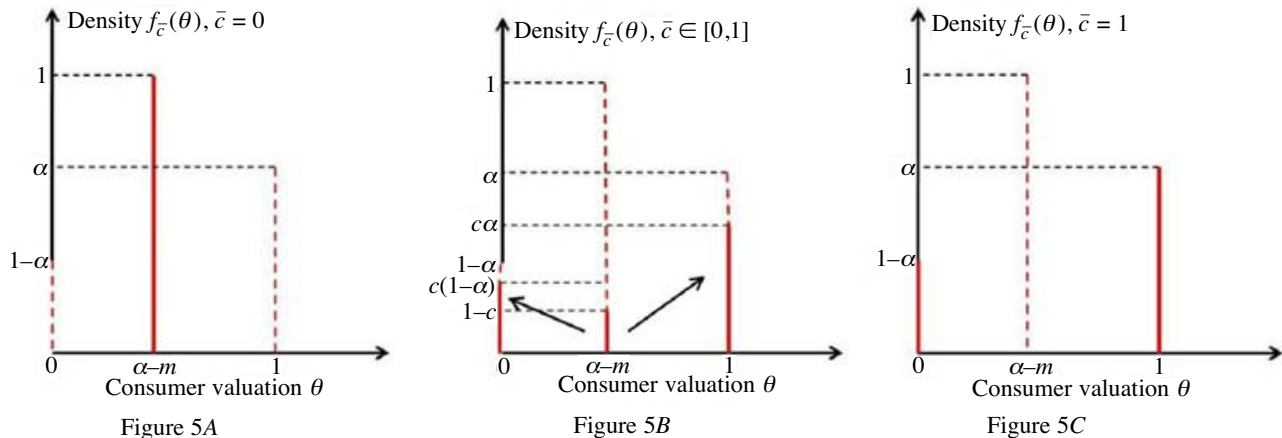

ter of the distribution (away from a $-m$ ) and towards the upper and lower tails, 1 and 0 , respectively. Dispersion of consumers' valuations final distribution increases. Hence, this translates into a rotation of the demand curve, in Johnson and Myatt terminology (represented in Figure 6).

Having the monopolist choosing final dispersion of the distribution of consumers' valuations is similar to Johnson and Myatt. Nevertheless, it is important to state one important difference between our structure and the one proposed in their paper. In particular, while in their model too, dispersion was endogenous and a variable of choice for the monopolist, in their setting the monopolist had the power to "impose" a certain amount of real information on its consumers. On the contrary, in our model it is consumers who have the final choice of acquiring information or not. This entails

FIGURE 6

\section{CHANGES IN $C_{1}$ LEAD TO A ROTATION OF THE DEMAND CURVE}

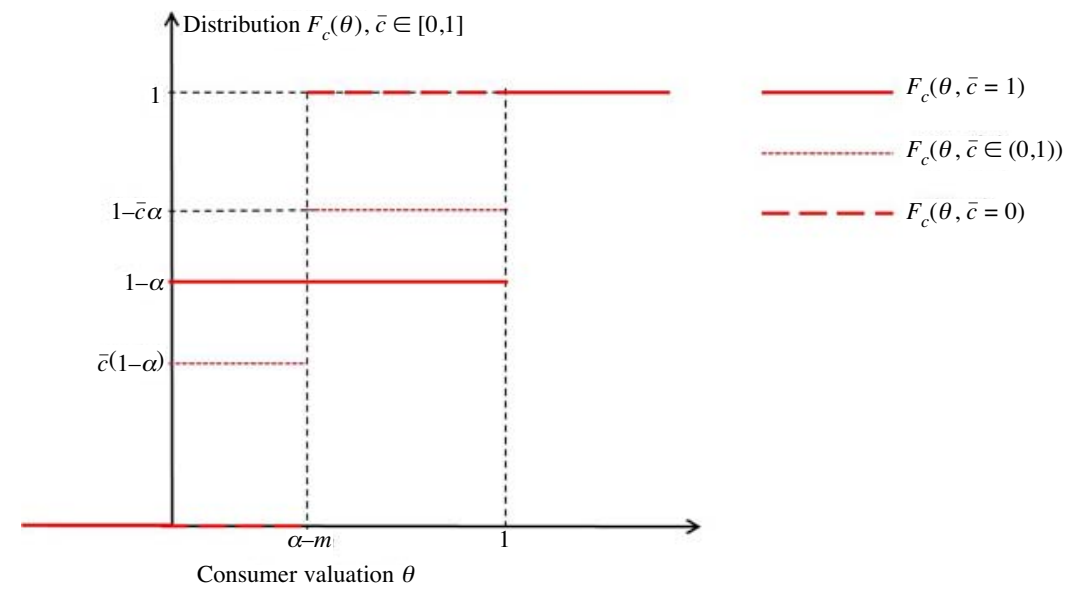


a non-continuous final distribution for consumers' valuations, which breaks one of the regularity conditions imposed by Johnson and Myatt $(2006)^{12}$.

However, our results are consistent with theirs, as we can see below. Figure 7 shows the optimal monopoly profits as a function of $c_{1}$, that is, as a function of dispersion, in our baseline model (Section 3). We observe that monopoly profits are, indeed, a " $U$-shaped" function of dispersion.

In addition, high-dispersion is complemented by niche production, as stated by Lemma 2 (the monopolist complements a maximum level of dispersion, $c_{1}^{*}=0$, with a price $P_{1}^{*}=1>\alpha$, that is, he sells to a small niche of high valuation consumers). Moreover, low dispersion is complemented by mass-market supply, as stated in Lemma 1 (the monopolist complements a minimum level of dispersion, $c_{1}^{*}=c_{\max }$, with a price $\left.P_{1}^{*}=\alpha-m\right)$.

According to Proposition 3 , the equilibrium is given by $c_{1}^{*}=0$ and $P_{1}^{*}=1$, that is, maximum dispersion and niche production. Johnson and Myatt's results indicate that a lower degree of maximum dispersion achievable (a lower dispersion in the distribution of consumers' (real) valuations) might shift the final decision of the monopolist from maximum dispersion to minimum one.

The following example illustrates this fact:

Example 9. There is a mass one continuum of consumers, each of them potentially interested in buying at most one unit of the product. Half of them have a (real) valuation for the product of $\alpha+2 m$, and the other half a (real) valuation of $\alpha+2 m$, where $m \in\left(\frac{1}{6} \alpha, \frac{1}{4} \alpha\right)$. Everything else is identical to the description of the model presented in Section 2 of this paper. Moreover, let's assume that $c_{\max }=\infty$.

We solve this example in a similar way to Section 3.

The monopolist has two main options. On one hand, he can $\operatorname{set} c_{1}^{*}=0$ and a price $P_{1}^{*}=\alpha+2 m$, with profits of $\pi_{1}^{*}=\frac{1}{2} \alpha+m$. On the other hand, he can set $c_{1}^{*}=\infty$ and a price $P_{1}^{*}=\alpha+2 m$, with profits of $\pi_{1}^{*}=\alpha-m-\varepsilon$. He prefers, however, the second case, as opposed to our model.

So, even if again, high dispersion is complemented with niche production (a marginal consumer above average) and low dispersion with mass-market supply, the monopolist optimally chooses low dispersion in this situation. The reason is that the maximum dispersion achievable is now lower.

Let's also look at the duopoly case. For any switching cost $s_{1} \in \Re$, the price set by the firm will be

$$
P_{1} \leq \min \left\{s_{1}, \alpha+2 m\right\}
$$

12 In particular, in JOHNSON and MYATT (2006), a given consumer is willing to pay up to $\theta$ for a single unit of a particular product, where $\theta$ is drawn from the distribution $F_{s}(\theta)$ with support on some $\left(\underline{\theta}_{s}, \bar{\theta}_{s}\right)$ (the parameter $s \in S \in\left[s_{L}, s_{H}\right]$ indexes a family of distributions). The authors assume $F_{s}(\theta)$ to be twice continuously differentiable in $\theta$ and $s$. 
Again, the firm has two options. It can set $c_{1}^{*}=0$ and a price $P_{1}^{*} \leq \min \left\{s_{1}, \alpha+2 m\right\}$, with profits of $\pi_{1}^{*} \leq \min \left\{\frac{1}{2} s_{1}, \frac{1}{2} \alpha+m\right\}$
Or, it can set $c_{1}^{*}=\infty$ and a price $P_{1}^{*} \leq \min \left\{s_{1}, \alpha-m\right\}$, with profits of $\pi_{1}^{*}=\min \left\{s_{1}, \alpha-m\right\}$

We have several cases. If $s_{1} \leq \alpha-m$, then we have $\frac{1}{2} s_{1} \leq s_{1}$ and the firm prefers the second case, equivalent to minimum dispersion and mass-market supply. If instead, $\alpha-m<s_{1}<\alpha+2 m$ then we have $\frac{1}{2} s_{1} \leq \alpha+\frac{1}{2} m<\alpha-m$, and again, the firm prefers the second case, minimum dispersion. For values of $s_{1}>\alpha+2 m$ we go back to the monopoly case.

Then in the duopoly case, the firm will prefer a minimum level of dispersion, independently of the value for the switching cost.

This finalizes our comparison between our Section 3, the monopoly case, and the optimal strategy for a monopolist treated in Johnson and Myatt, and gives a hint for our duopoly case results.

We now analyze a situation where competition is present, that is, Section 4 of our paper. We shall try to translate our duopoly case into Johnson and Myatt terminology, and see how our main results change within this situation.

In the case where competition is present, Johnson and Myatt acknowledge the existence of a new strategic effect of dispersion on firms' profits. In particular, under quantity competition, a change in dispersion influences opponents' output, and therefore an individual firm's profits.

\section{FIGURE 7}

\section{OPTIMAL MONOPOLY PROFITS AS A FUNCTION OF DISPERSION (SECTION 3)}

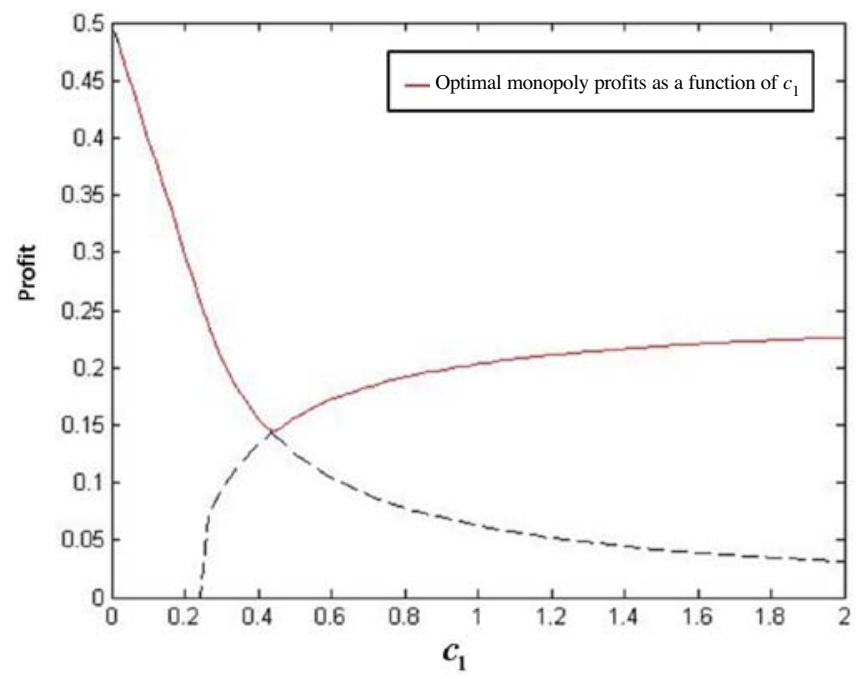


The authors ask how (or whether) an increase in competition changes a firm's preference for dispersion.

Remember that, in the monopoly case, Johnson and Myatt define a niche player whenever an increase in dispersion increases profits. On the contrary, they define a mass-market supplier whenever increased dispersion hurts profits. By imposing certain additional conditions ${ }^{13}$, the authors find that a mass - market supplier, that is, a firm that dislikes any local increase in dispersion, will continue to dislike increased dispersion when the number of competitors rises. The reason explaining their result is that heightened competition expands total industry output, making it more likely for the industry's marginal consumer to be "below average". This result indicates that firms in more competitive industries are more likely to be hurt by consumer learning. In conclusion, Johnson and Myatt find that their key results concerning the influence of dispersion on a firm's activities and profits carry over straightforwardly to a competitive industry.

As mentioned in Section 4, in our model, the main difference with the monopoly case is given by the fact that, in competition, the maximum price that the firm can charge is restricted, $P_{1}^{1^{*}} \leq s_{1}$.

Figure 8 shows duopoly profits as a function of $c_{1}$, that is, as a function of dispersion, in our baseline model (Section 4). Figure 8A shows duopoly profits for a low value of the switching cost $\left(s_{1} \leq \alpha-m\right)$, while Figure 8B shows duopoly profits for some high value of the switching cost $\left(s_{1}>\alpha-m\right)$.

We observe that results in both figures move away from our conclusions in the monopoly case. In the first place, we notice that for low values of the switching cost (Figure 8A), profits are no longer an " $U$-shaped" function of dispersion. In this situation, duopoly profits are strictly decreasing in the level of dispersion, and maxi-

FIGURE 8

OPTIMAL DUOPOLY PROFITS AS A FUNCTION OF DISPERSION (SECTION 4)

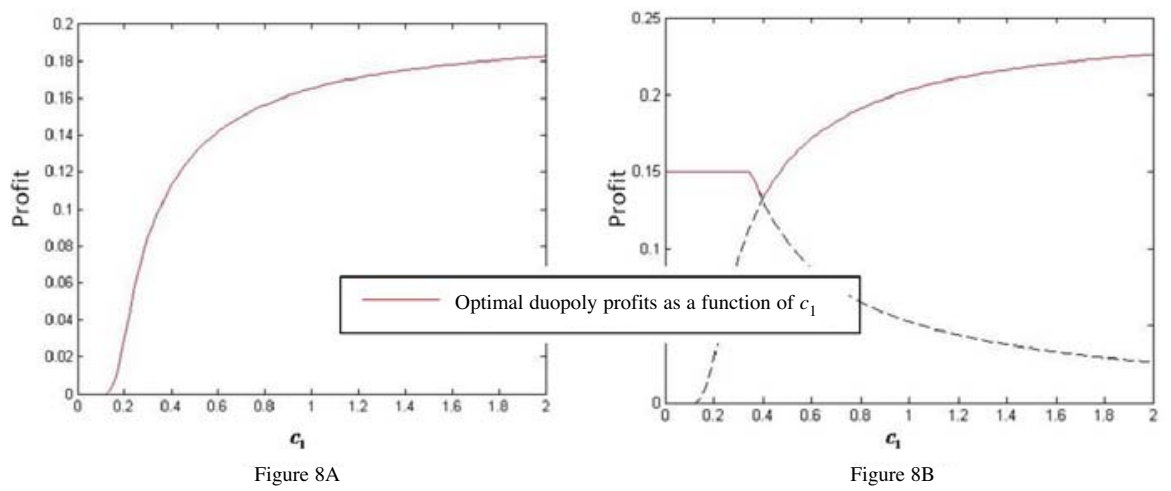

13 For the competitive industry case, Johnson and Myatt impose a new regularity condition on the family of demand curves considered, in particular, they impose the family of demand curves to be elasticity - ordered. This leads to a rotation - ordered corresponding family of marginal revenue curves. 
mized at $c_{1}^{*}=c_{\max }$, as opposed to the monopoly case. In the second place, for a somewhat higher value of the switching cost (Figure 8B), profits are, similar to the monopoly case, an " $U$-shaped" function of dispersion. But, as opposed to the monopoly case, they are now maximized at $c_{1}^{*}=c_{\max }$.

The interesting question is what makes the firm prefer a minimum level of dispersion in the duopoly case, instead of a maximum level of dispersion, which was preferred in the monopoly case.

As mentioned above, Johnson and Myatt's analysis of a competitive industry finds that under certain regularity conditions, a mass-market supplier under the monopoly case, that is, a firm with preference for a minimum level of dispersion, will prefer the minimum level of dispersion under a competitive framework too. However, the authors' results for the competitive industry don't account for a change in preferences between the two extreme levels of dispersion.

In Johnson and Myatt's paper, a change in preferences between the two extreme levels of dispersion could only be given by a change in the extreme levels of dispersion. It is obvious that not the same reason motivates the change in preferences in our model, as the two extreme levels of dispersion remain the same. Instead, as mentioned in Section 4 of this paper, it is the degree of competition in the market what makes the firm prefer one case or the other.

In particular, for a high degree of competition in the market (sufficiently low values of the switching cost ), exploiting the high types, that is, selling at a high price to a small niche of consumers is no longer possible, as the price is restricted by the switching cost. In this situation, maximum dispersion is no longer attractive, and increasing demand as much as possible becomes the new objective, achievable through a minimum level of dispersion.

Moreover, it is clear that if we choose some different extreme levels of dispersion instead of our baseline specification, such that a minimum level of dispersion is preferred in the monopoly case (see Example 9), this minimum level of dispersion will also surely be preferred in the duopoly case, independently of the degree of competition in the market, i.e., the value for the switching cost . The intuition behind this result is given by the fact that, as mentioned before, the monopoly case is the equivalent of a switching cost higher or equal to the valuation for the product of the high-type consumers ( in our baseline model, and in Example 9). It corresponds to the maximum price that can be charged by the monopolist to the high-types (a price equal to their valuation). If the monopolist, however, prefers minimum dispersion and a low price, then extracting the whole surplus from the high-types doesn't compensate for the loss in demand (all the low-types). But in the duopoly case, extracting all surplus from the high-types is not even possible, then the maximum dispersion strategy would lead to even lower profits than in the monopoly case (selling at an even lower price, to the same small demand), compared to the minimum dispersion one. So this last case will be clearly preferred. 


\section{Conclusions}

We have studied incentives for information provision in the mobile telephone market by means of a simple model, that examines interactions between information provision strategies and optimal pricing policies in an environment where consumers are heterogeneous not only in their valuations for the product, but also in the price they need to "pay" for information. In particular, agents have to incur a cost in order to learn their preferences.

We have found that, in our framework, a monopoly situation achieves the firstbest, even if it is not beneficial for the final consumer. On the contrary, too harsh competition leads to inefficiencies. The reason is that competition gives incentives for firms to "hide" information, leading to social welfare losses on several fronts (unnecessary information and risk-aversion costs are incurred). Under this setting, the optimal level of competition in the market will be quite low.

Information provision in our model can also be looked at from an advertising point of view. In this sense, our results are consistent with the ones presented by Johnson and Myatt (2006). However, their model mainly focuses on a monopoly case. In change, our analysis thoroughly covers competition.

It is, now, appropriate to end by highlighting some possible limitations and extensions to our analysis. Our duopoly model assumes that firms initially have half of the mass one continuum of consumers. We do not model the first stage of this game, in particular, the way in which these consumers end signed up to these firms. Hence, an important extension of our model would analyze this first stage. If we think of the switching costs as contractual, then they are probably a result of firms' optimal strategy in this first stage. Hence, regulating the switching costs might not be as straightforward as before, as not only they will affect equilibrium in our duopoly model, as seen in Section 5 , but also equilibrium of the first stage.

Moreover, and as mentioned above, when "hiding" information has a cost, the first best may be achieved under higher levels of competition. This is beneficial for consumers. Under this setting, regulating the cost of "hiding" information might be more efficient than directly regulating the switching costs. In particular, a law that standardizes mobile telephone invoices and tariffs might do the trick (however, a full analysis of this issue lies outside the scope of this paper).

In the last place, we propose switching costs as contractual, but different types of switching costs might exist. For example, we could have firms selling their products in different geographical areas. This would explain why the partition of consumers between firms in the first place. If the price of one firm increases in a considerable amount, consumers from its geographical area might consider taking a train and buying from the other firm. Of course, this would come at a cost. The intuition remains the same. However, possible interpretation of our results is different. Regulating switching costs is, again, not straightforward.

In conclusion, future research should examine the sensitivity of our results to our chosen specifications or applications, as the way in which we interpret switching 
costs or the significance of information provision may put regulation in a different light.

\section{References}

[1] BAR-ISAAC, H.; CARUANA, G. and CUÑAT, V. (2010): "Information gathering and marketing", Journal of Economics \& Management Strategy, Vol. 19, Issue 2, pp. 375401, Summer 2010

[2] JOHNSON, J. P. and WYATT, D., P. (2006): "On the simple economics of advertising, marketing and product design", American Economic Review, 96(3): 756-784

[3] KLEMPERER, P. (1987): "Markets with consumers switching costs", Quarterly Journal of Economics, Vol. 102, pp. 375-394.

[4] KLEMPERER, P. (1995): "Competition when consumers have switching costs: An overview with applications to Industrial Organization, Macroeconomics, and International Trade", Review of Economic Studies, Blackwell Publishing, Vol. 62(4), pages 51539 , October.

[5] MIRAVETE, E. J. (2003): "Choosing the wrong calling plan? Ignorance and Learning", American Economic Review, 93(1): 297-310.

[6] SHI, M.; CHIANG, J. and RHEE, B.-D. (2996): "Price competition with reduced consumer switching costs: The case of 'wireless number portability' in the cellular phone industry", Management Science, 52(1), 27-38.

[7] VIARD, B. (2007): "Do switching costs make markets more or less competitive?: The case of 800-number portability", Rand Journal of Economics, 38(1), 146-163 


\section{APPENDIX}

\section{Proof of Lemma 1}

As stated in the text, the monopolist has two main options: he can either set a price $P_{1} \leq \alpha-m$, or a price $P_{1}>\alpha-m$. Lemma 1 deals with the case where $P_{1} \leq \alpha-m$, so we proceed to analyze this case.

When $P_{1} \leq \alpha-m$, the monopolist solves the following maximization problem:

$$
\begin{gathered}
\quad \max _{P_{1}, c_{1}} \pi\left(P_{1}\right)=P_{1}\left[1-(1-\alpha) \frac{m+(1-\alpha) P_{1}}{c_{1}}\right] \\
F O C \Rightarrow P_{1}^{*}= \begin{cases}0 & \text { if } 0 \leq c_{1} \leq m(1-\alpha) \\
\frac{c_{1}-m(1-\alpha)}{2(1-\alpha)^{2}} & \text { if } m(1-\alpha)<c_{1} \leq m(1-\alpha)+2(1-\alpha)^{2}(\alpha-m) \\
\alpha-m & \text { if } m(1-\alpha)+2(1-\alpha)^{2}(\alpha-m)<c_{1} \leq c_{\max }\end{cases}
\end{gathered}
$$

Then profits for the monopolist as a function of $c_{1}$ are:

$$
\pi\left(c_{1}\right)= \begin{cases}0 & \text { if } 0 \leq c_{1} \leq m(1-\alpha) \\ \frac{\left[c_{1}-m(1-\alpha)\right]^{2}}{4(1-\alpha)^{2} c_{1}} & \text { if } m(1-\alpha)<c_{1} \leq m(1-\alpha)+2(1-\alpha)^{2}(\alpha-m) \\ (\alpha-m)\left[1-(1-\alpha) \frac{m+(1-\alpha)(\alpha-m)}{c_{1}}\right] & \text { if } m(1-\alpha)+2(1-\alpha)^{2}(\alpha-m)<c_{1} \leq c_{\max }\end{cases}
$$

So, to choose the optimal $c_{1}$, the monopolist maximizes profits with respect to it. The FOC obtained from this maximization is the following:

$$
F O C \Rightarrow \frac{\partial \pi\left(c_{1}\right)}{\partial c_{1}}= \begin{cases}0 & \text { if } 0 \leq c_{1} \leq m(1-\alpha) \\ \frac{\left[c_{1}^{2}-[m(1-\alpha)]^{2}\right]}{4(1-\alpha)^{2} c_{1}^{2}}>0 & \text { if } m(1-\alpha)<c_{1} \leq m(1-\alpha)+2(1-\alpha)^{2}(\alpha-m) \\ \frac{m(1-\alpha)(\alpha-m)+[(1-\alpha)(\alpha-m)]^{2}}{c_{1}^{2}}>0 & \text { if } m(1-\alpha)+2(1-\alpha)^{2}(\alpha-m)<c_{1} \leq c_{\text {max }}\end{cases}
$$

Clearly, monopoly profits for $P_{1} \leq \alpha-m$ increase with $c_{1}$, which leads us to an optimal $c_{1}=c_{\max }$, with a consequent price of $P_{1}=\alpha-m$. 


\section{Proof of Lemma 2}

Lemma 2 deals with the case where $P_{1}>\alpha-m$, so we proceed to analyze this case. When $P_{1}>\alpha-m$, the monopolist solves the following maximization problem:

$$
\begin{gathered}
\max _{P_{1}, c_{1}} \pi\left(P_{1}\right)=P_{1} \alpha\left[\frac{\alpha\left(1-P_{1}\right)}{c_{1}}\right] \\
F O C \Rightarrow P_{1}^{*}= \begin{cases}1-\frac{c_{1}}{\alpha} & \text { if } 0 \leq c_{1} \leq \frac{\alpha}{2} \\
\frac{1}{2} & \text { if } \frac{\alpha}{2}<c_{1} \leq c_{\max }\end{cases}
\end{gathered}
$$

Then profits for the monopolist as a function of are:

$$
\pi\left(c_{1}\right)= \begin{cases}\left(1-\frac{c_{1}}{\alpha}\right) \alpha & \text { if } 0 \leq c_{1} \leq \frac{\alpha}{2} \\ \frac{\alpha^{2}}{4 c_{1}} & \text { if } \frac{\alpha}{2}<c_{1} \leq c_{\max }\end{cases}
$$

Clearly, monopoly profits for $P_{1}>\alpha-m$ decrease with $c_{1}$, which leads us to an optimal $c_{1}=0$, with a consequent price of $P_{1}=1$.

\section{Proof of Proposition 6}

When $s_{1} \leq \alpha-m$, the result is straightforward. The firm can only set $P_{1}^{1} \leq s_{1} \leq \alpha-m$, and according to Lemma 1 , in this case profits are maximized when $c_{1}^{*}=c_{\max }$.

Instead, when $s_{1}>\alpha-m$, the firm has two options, either to set a price $P_{1}^{1}=\alpha-m$ and sell to both uninformed and informed high-type consumers, or to set a price as high as possible, $P_{1}^{1}=s_{1}$ and sell only to informed high type consumers:

$$
\text { 1. } c_{1}^{*}=c_{\max } \text { and } P_{1}^{1}=\alpha-m \Rightarrow \pi_{1}^{1}=(\alpha-m)\left[1-(1-\alpha) \frac{m+(1-\alpha)(\alpha-m)}{c_{1}}\right]
$$

2. $c_{1}^{*}=0$ and $P_{1}^{1}=s_{1} \Rightarrow \pi_{1}^{1}=\alpha s_{1}$ (as we saw that profits when $P_{1}^{1}=\alpha-m \downarrow$ with $c_{1}$ )

Then, profits in the second case are higher than in the first one if:

$$
\alpha s_{1}>(\alpha-m)\left[1-(1-\alpha) \frac{m+(1-\alpha)(\alpha-m)}{c_{1}}\right] \Rightarrow s_{1}>\bar{s}_{1}=\bar{s}_{1}^{1}=\frac{1}{\alpha}(\alpha-m)\left[1-(1-\alpha) \frac{m+(1-\alpha)(\alpha-m)}{c_{1}}\right]
$$

So the firm will prefer a case of complete information if the switching cost is high enough, as stated in Proposition 6. 


\section{Proof of Proposition 8}

We start by asking a question. If the firm can set an information cost of either (with a price $P_{1}^{1}=\frac{c_{1}-m(1-\alpha)}{2(1-\alpha)^{2}}$ ) or 0 (with a price $P_{1}^{1}=s_{1}$ ) in the case $s_{1}>\alpha-m$, when does it prefer the second case?

It prefers the second case when:

$$
\alpha s_{1}>\frac{\left[c_{1}-m(1-\alpha)\right]^{2}}{4(1-\alpha)^{2} c_{1}} \Rightarrow s_{1}>\overline{s_{1}^{2}}=\frac{1}{\alpha} \frac{\left[c_{1}-m(1-\alpha)\right]^{2}}{4(1-\alpha)^{2} c_{1}}
$$

We keep this result in mind for the time being.

We must understand that it is important whether the optimal

$$
c_{1}^{*}>2(1-\alpha)^{2}(\alpha-m)+m(1-\alpha)
$$

In proof of Lemma 1 we can see that this makes the difference, for the case $P_{1}^{1} \leq$ $\alpha-m$ and some positive information cost, between an equilibrium

with $P_{1}^{1}=\alpha-m$ and an equilibrium with $P_{1}^{1}=\frac{c_{1}-m(1-\alpha)}{2(1-\alpha)^{2}}$, and it determines how firmsprofits change with $c_{1}$.

We analyze these two cases separately:

1. Let's assume that the optimal information cost is such that

$$
c_{1}^{*}>2(1-\alpha)^{2}(\alpha-m)+m(1-\alpha) .
$$

There are several possibilities:

(a) $s_{1} \leq \mathrm{a}-m \Rightarrow P_{1}^{1}=s_{1}$.

The firm maximizes profits:

$$
\begin{gathered}
\max _{c_{1}} \pi\left(c_{1}\right)=s_{1}\left[1-(1-\alpha) \frac{m+(1-\alpha) s_{1}}{c_{1}}\right]-a-b c_{1} \\
F O C \Rightarrow c_{1}^{*}=\sqrt{\frac{m(1-\alpha) s_{1}+\left[(1-\alpha) s_{1}\right]^{2}}{b}}
\end{gathered}
$$

And we need to satisfy $c_{1}^{*}>2(1-\alpha)^{2}(\alpha-m)+m(1-\alpha)$, so we need

$$
b \in\left[0, \frac{m(1-\alpha) s_{1}+\left[(1-\alpha) s_{1}\right]^{2}}{\left[2(1-\alpha)^{2}(\alpha-m)+m(1-\alpha)\right]^{2}}\right]
$$


(b) $\alpha-m<s_{1} \leq s_{1}^{-1} \Rightarrow P_{1}^{1}=\alpha-m$

The firm maximizes profits:

$$
\begin{gathered}
\max _{c_{1}} \pi\left(c_{1}\right)=(\alpha-m)\left[1-(1-\alpha) \frac{m+(1-\alpha)(\alpha-m)}{c_{1}}\right]-a-b c_{1} \\
F O C \Rightarrow c_{1}^{*}=\sqrt{\frac{m(1-\alpha)(\alpha-m)+[(1-\alpha)(\alpha-m)]^{2}}{b}}
\end{gathered}
$$

And we need to satisfy $c_{1}{ }^{*}>2(1-\alpha)^{2}(\alpha-m)+m(1-\alpha)$, so we need

$$
b \in\left[0, \frac{m(1-\alpha)(\alpha-m)+[(1-\alpha)(\alpha-m)]^{2}}{\left[2(1-\alpha)^{2}(\alpha-m)+m(1-\alpha)\right]^{2}}\right]
$$

Also, we need $\alpha-m<s_{1} \leq s_{1}^{-1}$, so we need

$$
\alpha-m<\frac{1}{\alpha}(\alpha-m)\left[1-(1-\alpha) \frac{m+(1-\alpha)(\alpha-m)}{c_{1}}\right]
$$

then we need

$$
b \in\left[0, \frac{(1-\alpha)(\alpha-m)}{m+(1-\alpha)(\alpha-m)}\right]
$$

In conclusion, we need

$$
b \in\left[0, \frac{m(1-\alpha)(\alpha-m)+[(1-\alpha)(\alpha-m)]^{2}}{\left[2(1-\alpha)^{2}(\alpha-m)+m(1-\alpha)\right]^{2}}\right] \cap\left[0, \frac{(1-\alpha)(\alpha-m)}{m+(1-\alpha)(\alpha-m)}\right]
$$

Else, we will have $c_{1}^{*} \leq 2(1-\alpha)^{2}(\alpha-m)+m(1-\alpha)$ or $c_{1}^{*}=0$.

2. Let's assume that the optimal information cost is, instead, such that

$$
c_{1}^{*} \leq 2(1-\alpha)^{2}(\alpha-m)+m(1-\alpha) .
$$

There are several possibilities:

(a) $s_{1} \leq \frac{c_{1}^{*}-m(1-\alpha)}{2(1-\alpha)^{2}}<\alpha-m \Rightarrow P_{1}^{1}=s_{1}$

The firm maximizes profits:

$$
\max _{c_{1}} \pi\left(c_{1}\right)=s_{1}\left[1-(1-\alpha) \frac{m+(1-\alpha) s_{1}}{c_{1}}\right]-a-b c_{1}
$$




$$
F O C \Rightarrow c_{1}^{*}=\sqrt{\frac{m(1-\alpha) s_{1}+\left[(1-\alpha) s_{1}\right]^{2}}{b}}
$$

We need to satisfy

$$
s_{1} \leq \frac{c_{1}^{*}-m(1-\alpha)}{2(1-\alpha)^{2}}
$$

so we need

$$
s_{1} \in\left[\frac{m}{2(1-\alpha)} \sqrt{\frac{1-4 \alpha b(1-\alpha)^{2}}{1-4 b(1-\alpha)^{2}}-1}, \infty\right]
$$

(by solving the second order equation). This is equivalent to

$$
b \in\left[0, \frac{1}{4(1-\alpha)^{2}}\left[1-\frac{m^{2}}{4(1-\alpha) s_{1}^{2}+4 m s_{1}+m^{2}}\right]\right]
$$

Also, we need to satisfy $c_{1}^{*} \leq 2(1-\alpha)^{2}(\alpha-m)+m(1-\alpha)$, so we need

$$
b \in\left[\frac{m(1-\alpha) s_{1}+\left[(1-\alpha) s_{1}\right]^{2}}{\left[2(1-\alpha)^{2}(\alpha-m)+m(1-\alpha)\right]^{2}}, \infty\right]
$$

Then, for

$$
b \in\left[0, \frac{1}{4(1-\alpha)^{2}}\left[1-\frac{m^{2}}{4(1-\alpha) s_{1}^{2}+4 m s_{1}+m^{2}}\right]\right] \cap\left[\frac{m(1-\alpha) s_{1}+\left[(1-\alpha) s_{1}\right]^{2}}{\left[2(1-\alpha)^{2}(\alpha-m)+m(1-\alpha)\right]^{2}}, \infty\right]
$$

we could have an equilibrium that satisfies these conditions.

(b) $\frac{c_{1}^{*}-m(1-\alpha)}{2(1-\alpha)^{2}}<s_{1} \leq \bar{s}_{1}^{2} \Rightarrow P_{1}^{1}=\frac{c_{1}^{*}-m(1-\alpha)}{2(1-\alpha)^{2}}$

The firm maximizes profits:

$$
\begin{gathered}
\max _{c_{1}} \pi\left(c_{1}\right)=\frac{\left[c_{1}-m(1-\alpha)\right]^{2}}{4(1-\alpha)^{2} c_{1}}-a-b c_{1} \\
F O C \Rightarrow c_{1}^{*}=0
\end{gathered}
$$


Summarizing, we have obtained the following:

1. $s_{1} \leq \alpha-m$

The optimal information cost is given by

$$
c_{1}^{*}=\sqrt{\frac{m(1-\alpha) s_{1}+\left[(1-\alpha) s_{1}\right]^{2}}{b}}
$$

when

$$
b \in\left[0, \frac{m(1-\alpha) s_{1}+\left[(1-\alpha) s_{1}\right]^{2}}{\left[2(1-\alpha)^{2}(\alpha-m)+m(1-\alpha)\right]^{2}}\right] \cup\left[\left[0, \frac{1}{4(1-\alpha)^{2}}\left[1-\frac{m^{2}}{4(1-\alpha) s_{1}^{2}+4 m s_{1}+m^{2}}\right]\right] \cap\left[\frac{m(1-\alpha) s_{1}+\left[(1-\alpha) s_{1}\right]^{2}}{\left[2(1-\alpha)^{2}(\alpha-m)+m(1-\alpha)\right]^{2}}, \infty\right]\right]
$$

If $\mathrm{b}$ does not belong to this interval, the optimal information cost is $c_{1}^{*}=0$.

2. $s_{1}>\alpha-m$

The optimal information cost is given by

$$
c_{1}^{*}=\sqrt{\frac{m(1-\alpha)(\alpha-m)+[(1-\alpha)(\alpha-m)]^{2}}{b}}
$$

when

$$
b \in\left[0, \frac{m(1-\alpha)(\alpha-m)+[(1-\alpha)(\alpha-m)]^{2}}{\left[2(1-\alpha)^{2}(\alpha-m)+m(1-\alpha)\right]^{2}}\right] \cap\left[0, \frac{(1-\alpha)(\alpha-m)}{m+(1-\alpha)(\alpha-m)}\right]
$$

If $b$ does not belong to this interval, the optimal information cost is $c_{1}^{*}=0$. This gives us the value for $\bar{b}$ stated in the main text. 